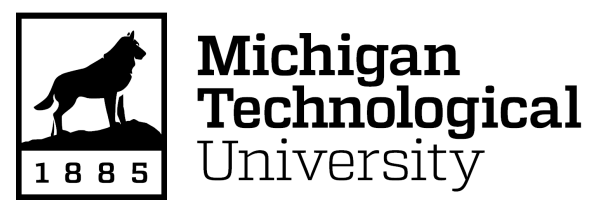

Michigan Technological University Digital Commons @ Michigan Tech

Dissertations, Master's Theses and Master's Reports

2017

\title{
A 3D Biomimetic Scaffold using Electrospinning for Tissue Engineering Applications
}

Samerender Nagam Hanumantharao

Michigan Technological University, snagamha@mtu.edu

Copyright 2017 Samerender Nagam Hanumantharao

\section{Recommended Citation}

Nagam Hanumantharao, Samerender, "A 3D Biomimetic Scaffold using Electrospinning for Tissue Engineering Applications", Open Access Master's Thesis, Michigan Technological University, 2017. https://doi.org/10.37099/mtu.dc.etdr/366

Follow this and additional works at: https://digitalcommons.mtu.edu/etdr

Part of the Biology and Biomimetic Materials Commons, Biomaterials Commons, Molecular, Cellular, and Tissue Engineering Commons, and the Polymer and Organic Materials Commons 


\title{
A 3D BIOMIMETIC SCAFFOLD USING ELECTROSPINNING FOR TISSUE ENGINEERING APPLICATIONS
}

\author{
By \\ Samerender Nagam Hanumantharao
}

A THESIS

Submitted in partial fulfillment of the requirements for the degree of MASTER OF SCIENCE

In Biomedical Engineering

MICHIGAN TECHNOLOGICAL UNIVERSITY

2017

C2017 Samerender Nagam Hanumantharao 
This thesis has been approved in partial fulfillment of the requirements for the Degree of MASTER OF SCIENCE in Biomedical Engineering.

\section{Department of Biomedical Engineering}

\begin{abstract}
Thesis Co-Advisor:
Thesis Co-Advisor:
\end{abstract}

Committee Member:

Department Chair:
Dr. Smitha Rao

Dr. Megan Frost

Dr. Ashwin Nair

Dr. Sean J. Kirkpatrick 


\section{Table of Contents}

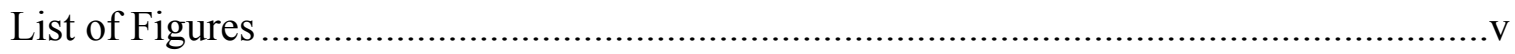

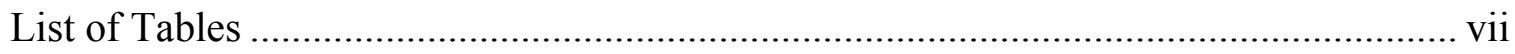

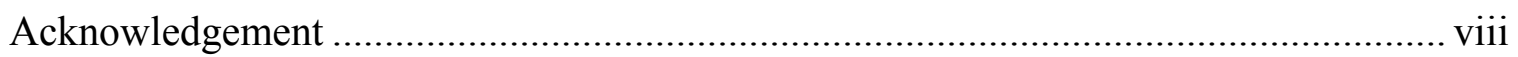

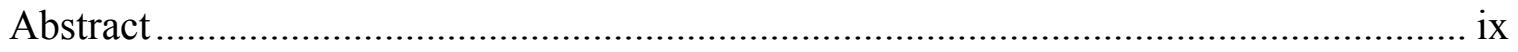

Chapter 1: Tissue scaffold engineering ..................................................................

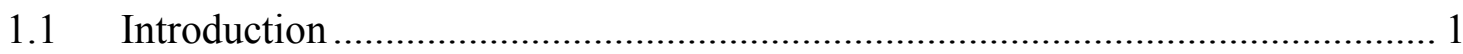

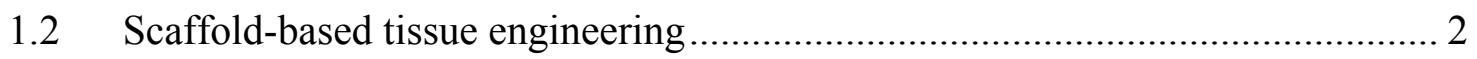

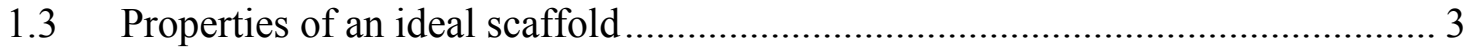

Chapter 2: $\quad$ Materials for tissue scaffold engineering .......................................................

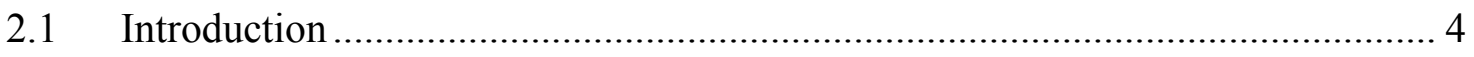

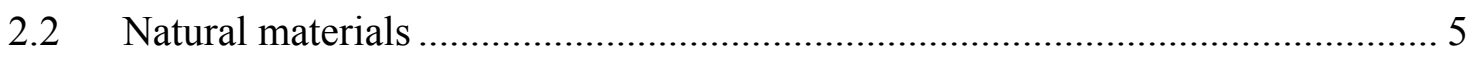

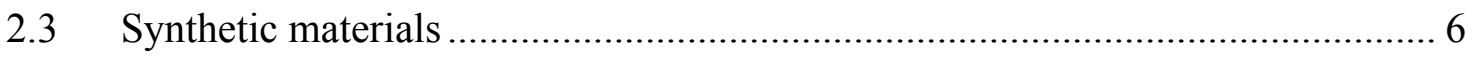

Chapter 3: Fabrication techniques ......................................................................

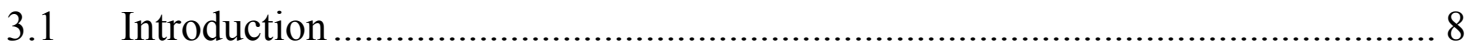

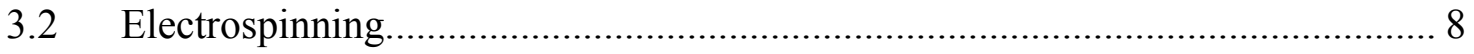

3.2.1 Parameters affecting electrospinning ....................................................... 11

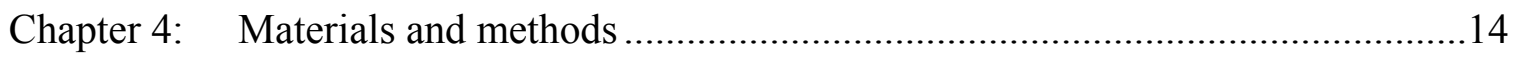

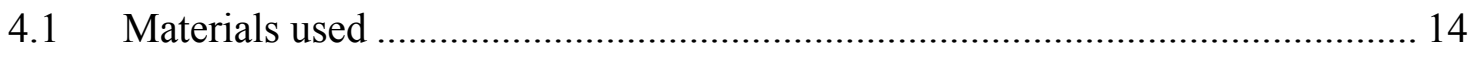

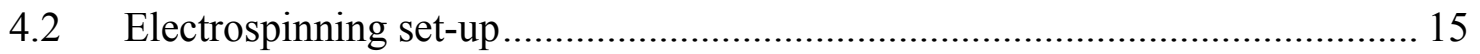

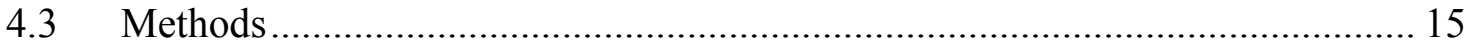

4.3.1 Characterization of nanofibers ............................................................... 15

4.3.2 Cell seeding experiments ................................................................ 18

Chapter 5: PCL based electrospun scaffolds .............................................................20

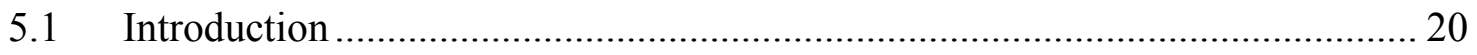

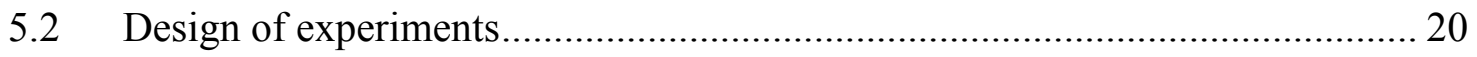

5.2.1 Honeycomb shaped scaffold ................................................................. 20 


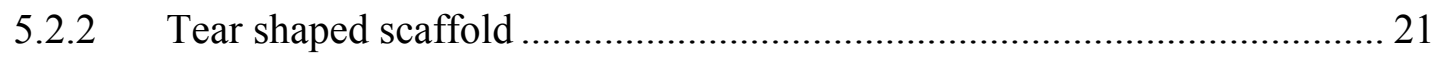

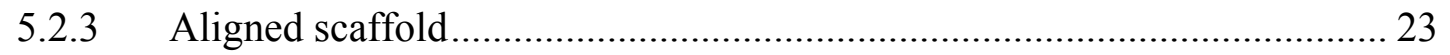

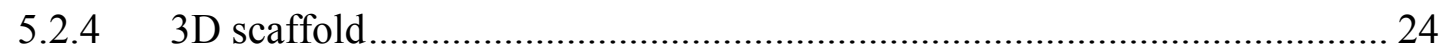

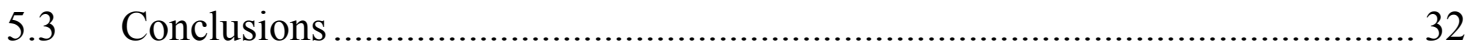

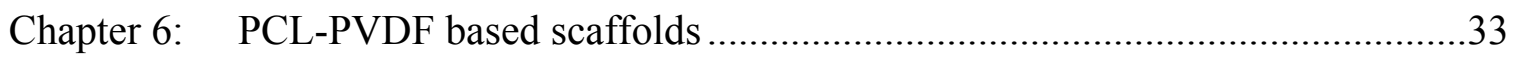

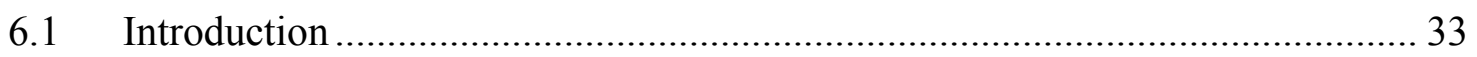

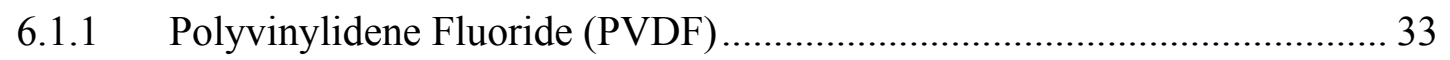

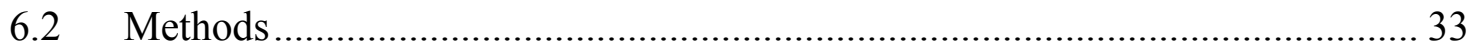

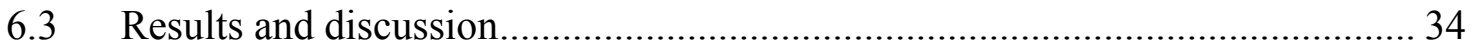

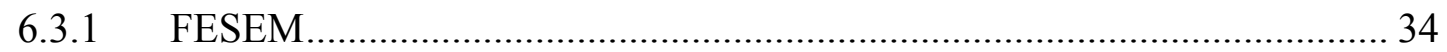

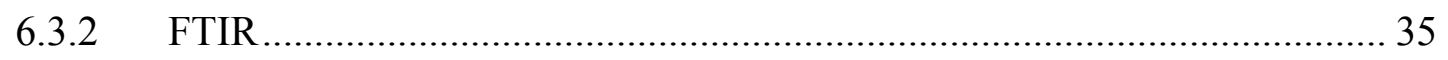

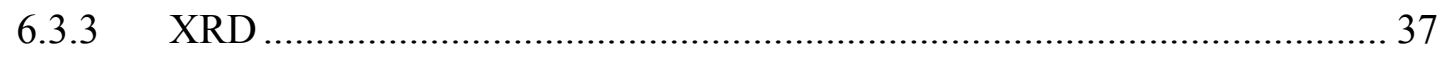

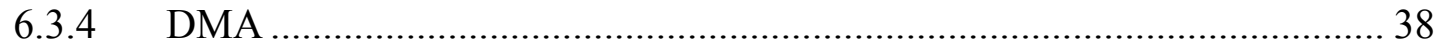

6.3.5 Cell seeding experiments ...................................................................... 39

Chapter 7: PCL-PANI-PVDF scaffolds...................................................................42

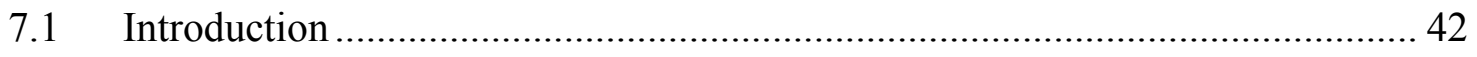

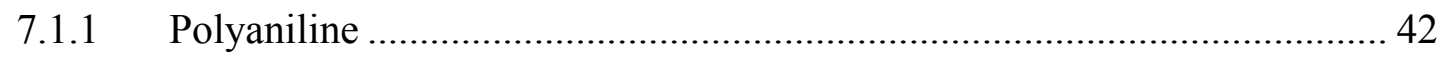

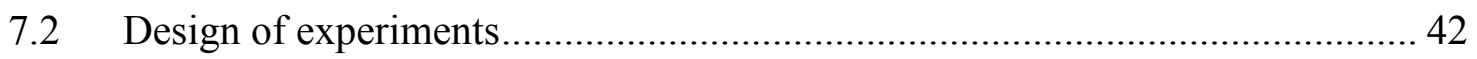

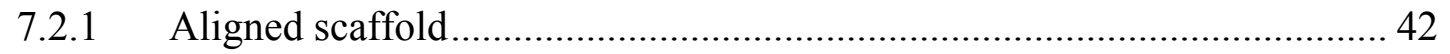

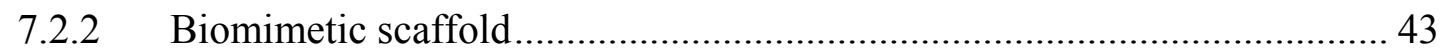

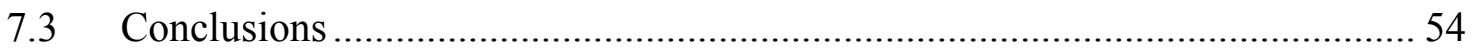

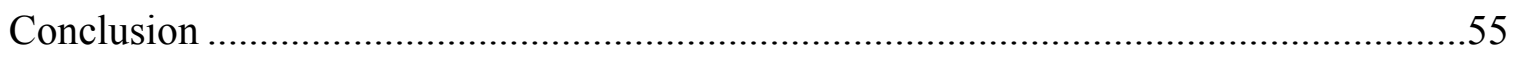

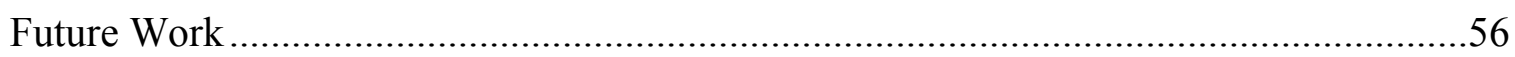

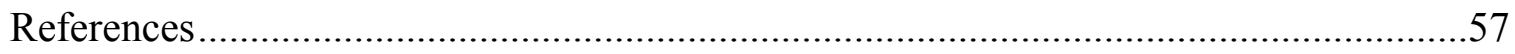




\section{List of Figures}

Figure 1.1 Representation of the main factors upon which scaffolds are designed........... 2

Figure 2.1 Classification of the biomaterials used for tissue scaffold engineering ........... 4

Figure 3.1 An illustration of the electrospinning set-up showing all the possible parameters

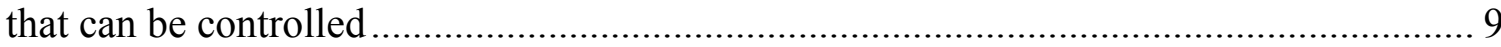

Figure 3.2 shows a representation of changes in shape of the fluid droplet during

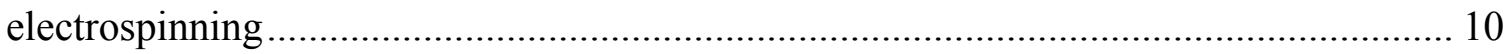

Figure 5.1 shows the FESEM images of the honeycomb shaped scaffold. Figure $5.1 \mathrm{~A}$ shows the high magnification image while the lower magnification image is seen in figure 5.1 B. The yellow colored dotted lines in figure 5.1 A highlight the honeycomb structure.

Figure 5.2 shows the FESEM image of the tear shaped scaffold ................................ 22

Figure 5.3 shows the FESEM images of the aligned scaffold. The inset shows the high magnification of the aligned fibers.

Figure 5.4 shows the FESEM images of the 3D scaffold. The inset shows the magnified image of the scaffold. 24

Figure 5.5 shows the FTIR spectrum of the 3D scaffold from a region of $400 \mathrm{~cm}^{-1}$ to $4000 \mathrm{~cm}^{-1}$. 25

Figure 5.7 shows the stress-strain-stiffness plot of the 3D scaffold. 28

Figure 5.8 shows the cells seeded on the scaffolds after immunofluorescent staining on days 1, 2, 3 and 7. The images on the left column show the DAPI stained cells while the images on the right show the cells stained with DAPI and Alexa Fluor. The blue color (DAPI) represents the nucleus and the green color (Alexa Fluor) represents the actin filaments. 30

Figure 5.9 shows the FESEM image of the scaffold after cell seeding. The cells were fixed after day 3 and imaged. Figure 5.9 A shows a low magnification image and figure 5.9 B shows a high magnification image of the scaffold seeded with cells. ........................... 31

Figure 6.1 shows the FESEM images of the PCL-PVDF scaffold................................. 34

Figure 6.2 represents the FTIR spectrum of the PCL-PVDF scaffold............................ 35 
Figure 6.3 shows the XRD spectrum of the PCL-PVDF scaffold ................................ 37

Figure 6.4 represents the stress- strain-stiffness plot of the PCL-PVDF scaffold ............ 38 Figure 6.5 shows the cells seeded on the scaffolds after immunofluorescent staining on days 1, 2, 3 and 7. The images on the left column show the DAPI stained cells while the images on the right show the cells stained with DAPI and Alexa Fluor. The blue color (DAPI) represents the nucleus and the green color (Alexa Fluor) represents the actin filaments.

Figure 6.6 shows the FESEM image of the scaffold after cell seeding. The cells were fixed after day 3 and imaged. Figure 6.6 A shows a low magnification image and Figure 6.6 B shows a high magnification image of the scaffold seeded with cells.

Figure 7.1 shows the FESEM image of the aligned scaffold. The inset image shows a high magnification image of the aligned scaffold. 43

Figure 7.2 shows the biomimetic scaffold after electrospinning. 44

Figure 7.4 shows the FTIR spectrum of the biomimetic scaffold from a region of $400 \mathrm{~cm}^{-1}$ to $4000 \mathrm{~cm}^{-1}$ 47

Figure 7.5 shows the XRD spectrum of the biomimetic scaffold............................... 49

Figure 7.6 shows the stress-strain-stiffness plot of the biomimetic scaffold. 50 Figure 7.7 shows the cells seeded on the scaffolds after immunofluorescent staining on days 1, 2, 3 and 7. The images on the left column show the DAPI stained cells while the images on the right show the cells stained with DAPI and Alexa Fluor. The blue color (DAPI) represents the nucleus and the green color (Alexa Fluor) represents the actin filaments. 52

Figure 7.8 shows the FESEM image of the scaffold seeded with cells after 7 days of growth. 53 


\section{List of Tables}

Table 5.1: A list of all the major peaks from FTIR spectrum and the description of the

vibrations 26

Table 5.2: The mechanical properties of the 3D scaffold calculated from the stress-strain-

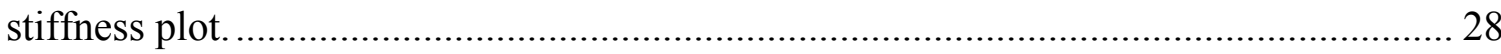

Table 5.3 summarizes the different PCL based scaffolds............................................... 32

Table 6.1: A list of all the major peaks corresponding to PVDF from the FTIR spectrum with a description of the vibrations and the electroactive phase ....................................... 35

Table 6.2: A list of all the major peaks from FTIR spectrum corresponding to PCL ...... 36 Table 6.3: The mechanical properties of the PCL-PVDF scaffold calculated from the stress-

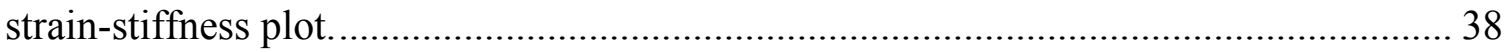

Table 7.1: A list of all the major peaks from FTIR spectrum specific to each polymer and

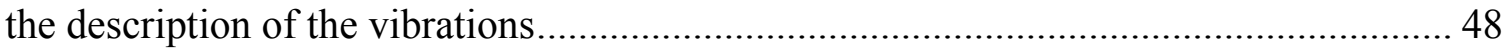

Table 7.2: The mechanical properties of the PCL-PANI-PVDF biomimetic scaffold

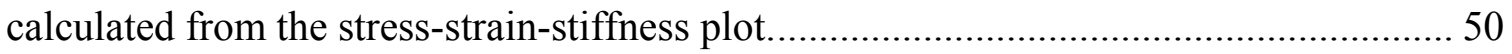

Table 7.3 summarizes the different PCL-PANI-PVDF based scaffolds............................ 54 


\section{Acknowledgement}

First and foremost, I would like to thank my family and friends for their continued motivation and support during my graduate studies. I would like to specifically thank my mother, father and maternal grandfather for their love and inspiration during all stages of my education. I would also like to thank my advisor, Dr. Smitha Rao for guiding me. Her infectious enthusiasm and creativity, positive criticism was truly inspirational and helped me pursue my ideas even after repeated failures. I would like to extend my gratitude to my professors from my undergraduate university; Dr. Thiagarajan Raman and my mentor in IIT- Madras; Dr. T.S Natarajan for their support and backing during various stages of my higher education. I would also like to thank my friends and colleagues for their support and valued feedback.

I would like to thank the faculty and staff at Michigan Technological University for providing the opportunities and the excellent infrastructure in the classroom as well as in the laboratory. I would like to specifically thank my committee members for their feedback and guidance. The environment at Michigan Technological University has been positive, vibrant and full of energy which is reflective of the research done. Finally, I would like to thank Mr. Owen Mills, Mr. Paul Fraley, Dr. Edward Laitila and Dr. Chito Kendrick from the Department of Materials Science and Engineering who helped me with the characterization of scaffolds. 


\section{Abstract}

Electrospinning holds great promise for designing functional 3D biomimetic scaffolds for tissue engineering applications. The technique allows for the reproducible fabrication of 3D scaffolds with control over the porosity and thickness. In this work, a novel method for the synthesis of a 3D electroactive scaffold using electrospinning from Polycaprolactone (PCL), Polyvinylidene Fluoride (PVDF) and Polyaniline (PANI) is reported. Additional scaffolds involving different morphologies of PCL, PCL-PVDF and PCL-PANI-PVDF were also fabricated and evaluated. The scaffolds were characterized using electron microscopy to visualize the morphologies. Infrared spectroscopy was used to confirm the presence of polymers and their respective phases in the scaffolds, and the degree of crystallinity was calculated using data from X-ray diffraction. Mechanical properties of the scaffolds were studied and the data was used to predict the cell-scaffold response. The method of preparation of the PCL-PANI-PVDF scaffolds of nanofibrous morphology provided control over the architecture of the scaffold. The synthesis process involved the preparation of doped PCL-PANI dispersions which were used as the core polymer solution. A PVDF polymer solution was used as the sheath solution. The synthesized scaffolds had many layers of fibers and were aligned. The scaffolds were seeded with H9c2 cells derived from rat cardiomyoblasts to check the cell-scaffold interactions. The cell line was chosen among many others because of the membrane potential of the cells and mechanical stiffness of scaffold required. Immunofluorescent staining for the actin filaments were used to evaluate the cell response to the scaffold. The scaffolds seeded with cells were also imaged using electron microscopy to check for scaffold infiltration and cell-scaffold interaction. Among all the scaffolds, PCL-PANIPVDF showed behavior of a true biomimetic scaffold with scaffold infiltration, cell alignment and cell proliferation. The scaffolds were used as fabricated after sterilization and no external treatment was required. This research can be used for the future fabrication of acellular scaffolds for different applications like organ engineering, neural interfaces and drug eluting scaffolds. 


\section{Chapter 1: Tissue scaffold engineering}

\subsection{Introduction}

Tissue engineering (TE) is the union of life sciences and engineering to grow new tissues to understand the physiology of cells in tissues, test drugs and to create tissue replacements or entire organs [1-5]. It is an alternative to reconstructive surgery using transplanted tissue because of associated problems like transplant rejection, pathogen transmission and an insufficient number of donor organs [6]. Engineering of tissues is also a suitable method to study the physiology of cells in a closely replicated 3D microenvironment [7]. This is essential to study cell-matrix interactions and the role of the matrices in various diseases. TE can be used to discover and test potential drug targets in a quicker manner than in vivo testing.

The primary objective of TE is to replicate the functioning of the natural tissue which requires knowledge about the tissue being engineered. This includes understanding the mechanical properties and electrical properties of the cells, signaling molecules and the extracellular matrix (ECM). To successful grow new tissues, the cells, ECM and the signaling molecules need to coexist as a single functional unit [8].

TE can be broadly divided into three categories based on the method used [9]:

- Cell isolates based therapies: Cell isolates or cell substitutes are used for replacement of only the specific cells which exhibit the function [10].

- Introduction of signaling molecules: Signaling molecules like growth factors are introduced to induce the production of new tissues [11].

- Scaffold-based tissue engineering: A 3D engineered artificial scaffold to closely mimic the natural ECM [12].

Of these three approaches, the current work focuses on engineering scaffolds as a means of engineering tissues. The use of scaffolds doesn't require the use of live animals for the growth of the tissue. The possibility of immune rejection is much lower and the tissues can be grown in a lab and transplanted later. The feasibility and relatively low-cost 
of the scaffolds is another benefit of using scaffolds for tissue engineering. Also, cells isolate based therapies and signaling molecules can be used along with scaffolds.

\subsection{Scaffold-based tissue engineering}

A scaffold is engineered and fabricated specifically for the cells in order to form tissues [13]. The cells are seeded directly on the engineered scaffold and grown in a cell- specific nutrient rich media.

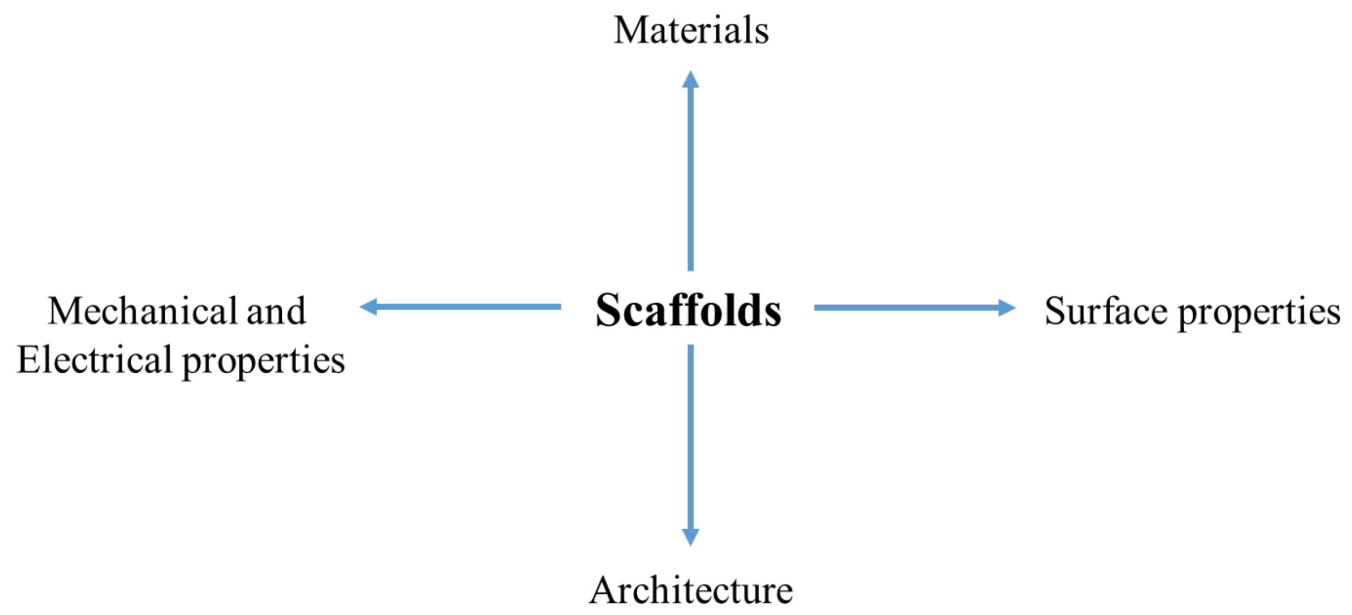

Figure 1.1 Representation of the main factors upon which scaffolds are designed.

Figure 1.1 shows a representation of the four major factors based on which scaffolds are designed. The materials used for fabrication can either be natural polymers or synthetic polymers or a combination of the two. The materials used need to be biocompatible and in some cases biodegradable [14]. The surface properties like hydrophobicity and hydrophilicity play a role in cellular attachment [15].Surface hydrophobicity is not preferred as it prevents cellular attachment. The architecture of the scaffold decides the nature of 3D surface that is available for the cell. A 3D geometry helps in enhancing the cell- matrix interactions [16]. The mechanical and electrical properties of the scaffold need to replicate the extra cellular matrix of the cell as they are essential for cellular differentiation and proliferation. An optimal mechanical strength is necessary for cellular 
migration and electrically active cells need electrical signals for proliferation and cellular alignment $[17,18]$.

\subsection{Properties of an ideal scaffold}

An ideal scaffold is one which can mimic the 3D microenvironment of the cell. The engineered scaffold needs to have certain key properties to make it an ideal scaffold [19]. These include:

- Ensure cellular penetration to all layers of the scaffold [20].

- Allow appropriate mass transport across the different layers of the scaffold [21].

- Match the mechanical stiffness of the cells very closely for cell-matrix interactions promoting cellular proliferation, differentiation and adhesion [22].

- Provide excitability and ensure axial cellular alignment for electroactive cells like cardiomyocytes and skeletal muscles as the membrane potential regulates the intercellular signaling pathways [23, 24].

- Promote cellular infiltration through an optimal porous morphology for uniform absorption of nutrient media increasing the total available surface area for cells [25].

- Provide a high surface area to ensure that there is a higher cell density per scaffold [26]. 


\section{Chapter 2: Materials for tissue scaffold engineering}

\subsection{Introduction}

The materials for the scaffolds are specifically chosen based on the type of tissue being grown as it defines the type of interaction with the cell $[27,28]$. The requirements for an ideal scaffold hence limits the number of materials that can be used for fabrication of scaffolds [29]. The major properties that a material needs to possess to be considered for tissue scaffold engineering are:

- Biocompatibility: The material should not be toxic or degrade to produce toxic byproducts [30].

- Anti-immunogenicity: The material should not initiate an adverse immune reaction [31].

There are other properties like biodegradability, which are essential in certain cases but is not a must.

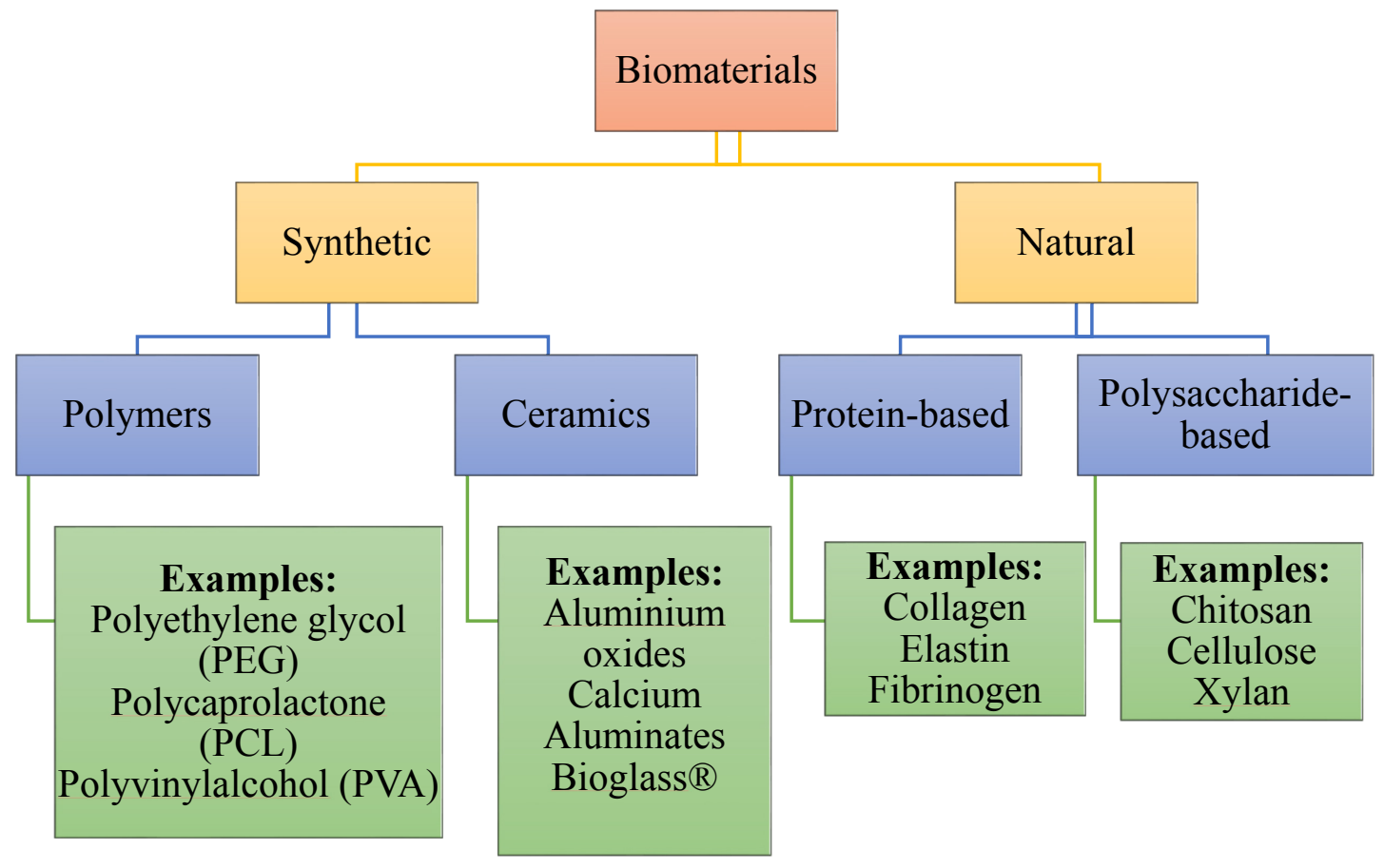

Figure 2.1 Classification of the biomaterials used for tissue scaffold engineering 
The organization chart in figure 2.1 shows the classification of the biomaterials used for tissue scaffold engineering with examples. The fabrication methods are chosen based on the type of materials used to a large extent.

\subsection{Natural materials}

Natural materials are those that have been extracted from plants or animals. They can be broadly divided into protein-based and carbohydrate-based scaffolds [32]. These can be further divided into plant-based and animal-based scaffolds. The biomaterials based on animal proteins can be further divided into tissue-based or blood-based depending on the location of the protein. Tissue proteins like collagen and gelatin are components of the natural human ECM and consequentially these materials have been derived and used for scaffolds to imitate the 3D microenvironment present in the native tissues. Proteins commonly found in the blood like fibrinogen have very good mechanical properties, which make them excellent candidates for scaffold engineering. The elastic modulus and recognition by a wide range of cells make them attractive materials for scaffold applications $[33,34]$. Plant proteins like zein derived from corn, gluten from wheat and aloe vera powder have been used for scaffold engineering because of their low net negative charge which decreases the hydrophobicity and increases solubility in solvents in relation to animal-based proteins [35-37]. In addition, the materials have known properties like anti-microbial and anti-inflammation. Polysaccharide-based scaffolds can also be broadly divided based on their origin: animal and plant. The plant-based polysaccharides like cellulose have excellent mechanical properties, biocompatibility and are easily available [38]. The animal-based polysaccharides like chitosan have anti-microbial and antiinflammatory properties. They have high mechanical strength and can be fabricated into biodegradable scaffolds [39].

The advantages of using natural materials for scaffold fabrication are:

- Biocompatibility

- Biodegradability 
- Biological response: These materials are easily recognized by the cells and integrate well with the cells.

- Other favorable properties like mechanical strength, anti-tumorigenicity, antiimmunogenicity and anti-microbial activity are specific to certain materials.

The disadvantage of using natural materials for scaffolds are:

- There is a limited quantity of the raw materials available for the extraction of these materials

- A high degree of purity of the materials is required for scaffold engineering to prevent immunogenic reactions. For example, there have been concerns that bovine derived collagen can cause Bovine spongiform encephalopathy.

- The extraction process is expensive for most materials thus driving-up the cost of scaffolds

- The materials cannot undergo many chemical reactions because of its high molecular size thus, limiting its tunability and applications.

\subsection{Synthetic materials}

Synthetic materials can be broadly divided into ceramics and polymers $[40,41]$. Bio ceramics bond with the cells quickly and hence have been actively investigated as tissue scaffold materials apart from various other applications. Controllable porosity is another factor which has brought significant interest to bio ceramics [42]. However, they are generally used along with a combination of polymers because of their brittleness [43]. Synthetic polymers offer tremendous options with regards to the materials. The option to tune the molecular weight, ability to co-polymerize to obtain favorable properties and control over the surface charges has furthered interest in synthetic polymers.

These polymers can be further classified into biodegradable/resorbable and nonbiodegradable polymers. The biodegradable or bioresorbable polymers are those which degrade inside the body into harmless products which can be processed by the body like organic salts, water, gases, urea etc. The scaffolds can be degraded by hydrolytic methods 
or enzymatic methods. The biodegradable polymers are designed to degrade once the intended purpose is completed [44]. This can be advantageous in some cases when the risk of infection is high or when the intended life-time is few months. Examples of biodegradable synthetic scaffolds are poly ( $\alpha$-esters) and polyglycolides. Nonbiodegradable materials do not degrade as quickly as the biodegradable synthetic polymers and hence are used for applications where the life-time of the product is high (few years). The design of scaffolds based on non-biodegradable materials thus need to be nonimmunogenic and non-thrombogenic. These materials are usually used when the mechanical strength is required for a considerable amount of time without any loss in the properties. Additionally, these scaffolds are tough and used for wound healing applications. 


\section{Chapter 3: Fabrication techniques}

\subsection{Introduction}

There are numerous methods by which scaffolds can be manufactured using the materials described in the previous chapter. Some of the methods are sol-gel casting, particulate leaching, fiber bonding, phase separation, extrusion molding, 3D printing, freeze drying and electrospinning [45-52]. Electrospinning is one of the most promising techniques for scaffold fabrication, because it can produce various architectures of scaffold in an economical and easy manner [53].

\subsection{Electrospinning}

Electrospinning is an electric field-assisted technique for the continuous production of fibers from a few microns in diameters to ultrathin fibers in tens of nanometers. It is versatile, flexible and can be easily scaled up for industrial production [54, 55]. Electrospinning has been applied for the fabrication of a range of materials such as polymers, nanocomposites and ceramics [56]. This technique has been used widely in tissue engineering for scaffold fabrication because of the ability to produce fibrous scaffolds [57].

Even though the effects of electric fields on droplets have been researched from the $17^{\text {th }}$ century, it was not until 1900 that the technique was patented by J.F. Cooley. The technique was commercialized by Formahls in 1934-1944 through a string of patents. However it was in the early 1990s that the technique gained popularity in academic research when Doshi and Reneker demonstrated the fabrication of fibers from a variety of organic polymers [58]. This spurred research into electrospinning leading to many modifications to the technique and increased the field of application. 


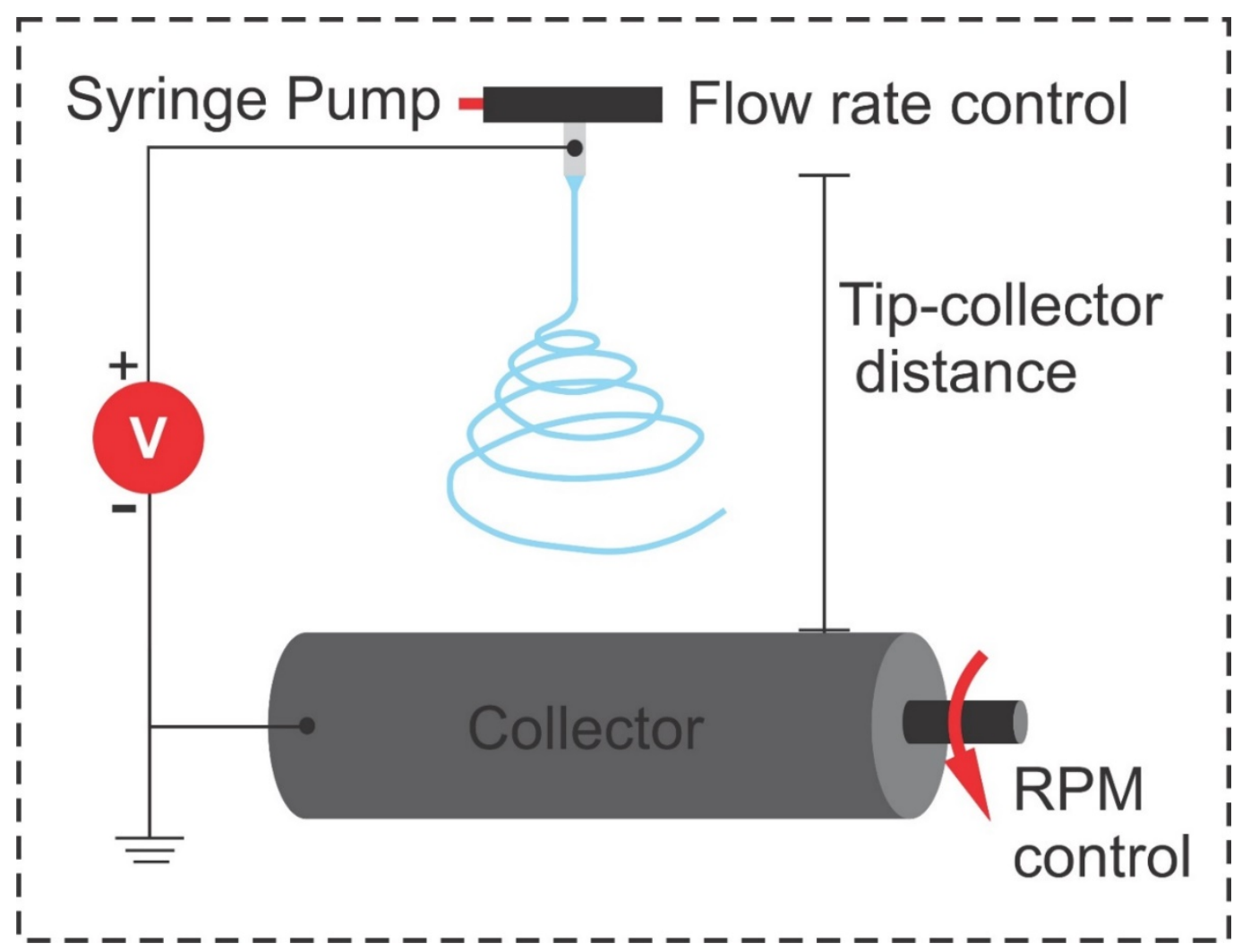

Figure 3.1 An illustration of the electrospinning set-up showing all the possible parameters that can be controlled

The illustration in figure 3.1 illustrates the essential configuration of the electrospinning apparatus. It consists of a spinneret, syringe pump, grounded collector and a high voltage source. Electrospinning uses electric field, typically $>0.5 \mathrm{kV} / \mathrm{cm}$ applied to the tip of a spinneret/nozzle through which the polymer flows out in droplets. The viscosity of the solution typically needs to be in between $200-4000 \mathrm{cP}$. The feed rate of the polymer solution is controlled with a syringe pump. The forces acting on the droplets are gravity, surface tension, and electrical forces which balance each other to form a Taylor cone. This was documented by Reneker et al who showed the Taylor cone formation during the 
electrospinning process as it occurred captured using a camera with high shutter speeds [59].

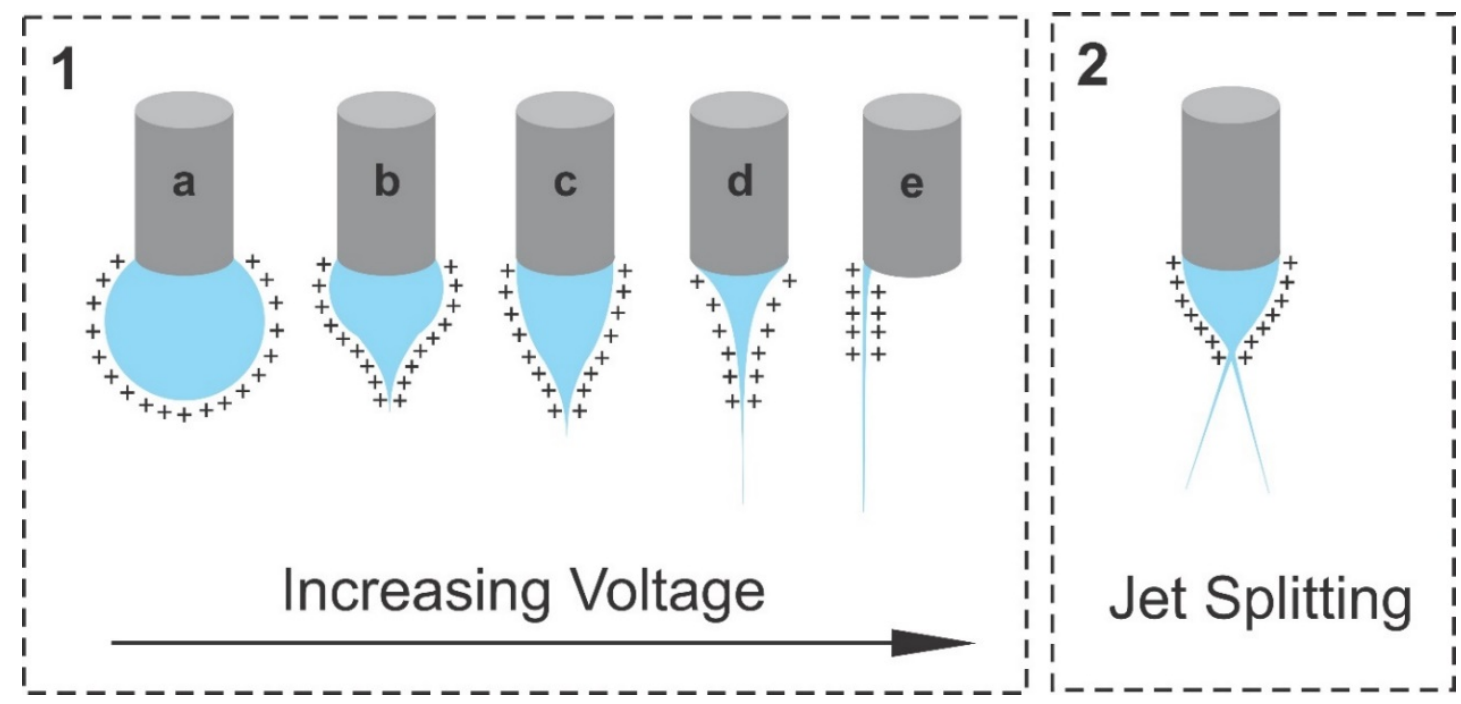

Figure 3.2 shows a representation of changes in shape of the fluid droplet during electrospinning

When high voltage is applied to the polymer droplets, the droplets containing the polymer chains undergoes two types of major forces which act in opposite directions: Electric stresses and gravity, and surface tension of the droplet. When the electric stresses and gravity are equal to the surface tension of the droplet, a Taylor cone is formed over a narrow region of the electric stresses as seen in figure 3.2.1 d. When the electric field is increased, a liquid jet is ejected from the nozzle tip. Three types of instabilities are present during the electrospinning process. The first is the Rayleigh instability occurring due to the opposing forces acting on the jet and is axisymmetric. The second instability is also axisymmetric while the third is non-axisymmetric and is known as whipping instability. The polarized jets has repulsion from the charge density present on the surface of the jet which tends to increase surface area while the surface tension tends to decrease the surface area. This instability causes the jet to break into tiny droplets if the surface tension of the polymer solution is low $\mathrm{m}$ as in the case of electrospraying. As the jet travels towards the grounded collector, the jet becomes elongated. The solvents evaporate at different distances 
from the collector based on their boiling points and the jets gets separated because of mutual repulsion. This phenomenon is known as splaying. Due to splaying and jet elongation, the diameters of the fibers increases and continuous fibers are formed. The jet whirls and is unstable during the bending and stretching of the fibers. This has been studied in detail and modelled by Hohman and colleagues [60, 61].

The electrospinning apparatus has been modified by changing the type of grounded collectors used to produce aligned fibers for scaffold applications. Some of the modifications are parallel plate method, rotating collector method, rotating wire drum collector and disc collector. Magnetic field assisted alignment and use of counter electrodes as collectors are other modifications which have been used [62].

\subsubsection{Parameters affecting electrospinning}

There are certain parameters which control the end structure or even the process; either electrospinning or electrospraying which are discussed in detail below. Apart from these parameters, the size of the nozzle and coaxial gas shields affect the electrospinning process $[63,64]$.

\subsubsection{Applied voltage}

The applied voltage plays a major role in the resultant structures. Electrospinning occurs when the electric field can overcome the surface tension of the fluid as seen in figure 3.2.1. With constant polymer flow rate and tip-nozzle distance, as the voltage is increased the Taylor cone forms and with further increase, the Taylor cone recedes into the nozzle. The voltage also plays a role in the diameter of the fibers over a short range [65]. Zhang et al. demonstrated the role of voltage on morphologies of polyvinyl acetate fibers [66]. With increasing voltage, the diameters of the resulting fibers decreases. Beyond this point, with further increase in voltage, the instability increases causing beading in the fibers. The increase in applied voltage also helps in aligning the fibers along the electric field axis increasing the crystallinity as demonstrated by Ero-Phillips on poly(L-lactic acid) fibers [67]. 


\subsubsection{Polymer feed rate}

With slower feed rate, the droplets are polarized well and this leads to production of continuous non-beaded fibers. A slower flow rate is recommended when high boiling point solvents or polar solvents are used so that there is enough time for the solvents to evaporate as demonstrated by Zhang and colleagues [68]. The flow rate also plays a role in the diameter of the fibers with a lower flow rate having thicker diameter fibers and higher polymer flow rate leading to thinner fibers [69].

\subsubsection{Tip-collector distance}

The tip-collector distance decides the electric field being applied between the tip of the nozzle and the grounded collector. If the distance is too short, the solvent won't evaporate and a longer distance will lead to beaded fibers [70]. It has also been demonstrated that increasing the tip-collector distance is favorable for the formation of thinner fibers. Near-field electrospinning uses a very small distance between the tip of the nozzle and collector with a proportional increase in applied voltage [71]. This technique has been used to reduce splaying and control the deposition of the fibers.

\subsubsection{Ambient conditions}

Temperature and humidity play a role in the formation of Taylor cone, rate of evaporation of solvent, diameter and the porosity of the fibers. Casper et al. demonstrated the effects of the ambient parameters on Polystyrene fibers during electrospinning [72]. A higher temperature will lead to a higher rate of evaporation of the solvent from the Taylor cone leading to clogging whereas a lower temperature will lead to an unstable Taylor cone formation. The temperature also plays a role in the diameter of the fibers with a higher temperature leading to thinner fibers whereas thicker fibers are obtained with lower temperatures. Higher humidity leads to the formation of porous fibers whereas low humidity leads to non-porous fibers. This is because of the water vapor present which evaporates during the electrospinning process [73]. 


\subsubsection{Solution parameters:}

The sol-gel which is prepared and used as the feed solution during electrospinning plays an important role in the resultant nanofibers. The polymer used, concentration and its molecular weight are some of the factors that can be controlled. Wannatong et al. studied the effect of solvents on the morphology of polystyrene fibers fabricated by electrospinning [74]. An increase in molecular weight increases the viscosity and increases the diameter of the fibers. Surfactants can be added to reduce the surface tension of the resulting solution. The use of surfactants have been used for jet-splitting to fabricate electro-netted nanostructures [75]. The viscosity of the solution needs to be in a certain range for electrospinning. A lower viscosity leads to beads and higher viscosity leads to clogs or improper electrospinning. The viscosity in turn is directly proportional to the molecular weight and concentration of the polymer [76]. The type of polymer plays a role as the net negativity and the type of bonds in the polymer decides the nature of solvents in which it is soluble, which in turn affects the sol-gel. Some polymers like PCL are soluble in a wide range of organic solvents while poly alcohols are soluble in water. 


\section{Chapter 4: Materials and methods}

The following section elaborately reviews the materials that were used for the fabrication and characterization of the scaffolds. The methods used for fabrication and characterization of the scaffold is briefly discussed.

\subsection{Materials used}

The solvents used for dissolution/suspension of the polymers for the sol-gel process before electrospinning were Methanol (Sigma Aldrich, USA; 99\% Pure), Chloroform (Sigma Aldrich, USA; 99.8\% Pure), DMF (Macron Fine Chemicals; USA (ACS grade)) and Acetone (Sigma Aldrich, USA; ACS reagent: 99.5\% Pure)

The other solvents that were used are Formaldehyde (16\% solution; Thermo Scientific, USA) for fixing the samples after cell seeding, Ethanol (Pharmaco-Aaper, USA; ACS/USP Grade 190 Proof) and Isopropyl Alcohol (VWR Analytical grade, USP, 99\% Purity). HMDS 16700 Electron Microscopy Sciences, USA and DMSO (Cellgro, USA) was used as an alternative for critical drying point before visualizing the cells under the scanning electron microscope.

The polymers used were PDMS (Sylgard 184; Dow Corning, USA), PCL (Scientific Polymer Products, USA; Mw= 70,000 GPC), PVDF (Sigma Aldrich; France; $\mathrm{Mw}=534,000$ ), PVDF (Aldrich Chemistry, France; $\mathrm{Mw}=180,000$ by GPC), Emeraldine base (Aldrich Chemistry, USA; $\mathrm{Mw}=50,000$ ), and Emeraldine salt (Aldrich Chemistry,

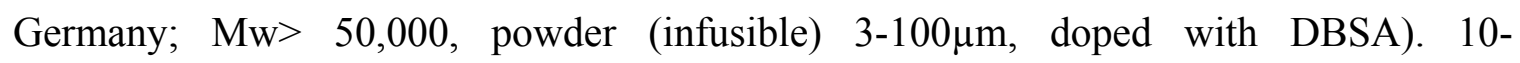
Camphorsulfonic acid ( $\beta$ ) (98\% Purity; Aldrich Chemistry; France) was used for the protonation of the emeraldine base to the salt form.

The cell culture medium used in these experiments were DMEM /F12 (1:1) (1X) (Life Technologies, USA), DMEM (1X with $4.5 \mathrm{~g} / \mathrm{L}$ glucose), L-glutamine, and sodium pyruvate (Life Technologies, USA) supplemented with $100 \mathrm{U} / \mathrm{ml}$ penicillin, and $100 \mu \mathrm{g} / \mathrm{ml}$ streptomycin in $10 \%$ FBS (Life Technologies, USA) under $5 \% \mathrm{CO}_{2}$ atmosphere at $37^{\circ} \mathrm{C}$. 
Alexa Fluor 488 (Phalloidin; 300U; Life Technologies, USA) to stain the F-actin and DAPI (Life Technologies, USA) to stain the A-T regions in the nucleus were used.

\subsection{Electrospinning set-up}

Two different electrospinning set-ups were used in the work reported here:

1. A custom-built electrospinning equipment in a controlled (humidity) room with an option to use either a rotating disc collector or a flat aluminum substrate as the collector.

2. A EM-DIG (IME Technologies, Netherlands) electrospinning unit fitted with a rotating cylinder (EM-RTC, IME Technologies, Netherlands). The needle tip could either be a single needle or a coaxial needle (ID: $0.4 \mathrm{~mm}$, OD: 1mm; EM-CAX; IME Technologies, Netherlands). The relative humidity was maintained around $20-40 \%$ using a desiccant (silica gel) in an enclosed chamber. All the experiments were carried out at temperatures ranging from $19-25^{\circ} \mathrm{C}$. The tip-collector distance was maintained constant at $0.17 \mathrm{~m}$. Two separate syringe pumps (Harvard Pumps, EP-H11) were used to control the flow rate.

\subsection{Methods}

The following are the general methods that were used for the characterization of the scaffolds and cell seeding experiments.

\subsubsection{Characterization of nanofibers}

\subsubsection{Field Emission Scanning Electron Microscopy (FESEM)}

Field Emission Scanning Electron Microscopy (FESEM) uses the electrons emitted by field emission of a crystal to interact with the samples in an ultralow vacuum environment. Electrons are used instead of the traditional light source. Electromagnetic lenses are used to focus the electrons onto the samples. The condenser and apertures help in blocking out the stray electrons ensuring a concentrated source of electrons. The electrons interact with the samples and get scattered onto a fluorescent screen. An image 
of the sample is obtained based on the backscattering or the secondary electrons. Conductive samples can be directly viewed under the FESEM. The rest of the samples need to be sputter coated with a thin layer of noble metals. FESEM is a surface technique and can be used to view the surface of the samples alone in a greyscale. FESEM allows quick way to visualize fibers which are in the nanoscale. It also helps in viewing the fibers and cells in high resolution.

The samples are initially sputter coated with a $5 \mathrm{~nm}$ thick coating of $\mathrm{Pt} / \mathrm{Pd}$. The polymer scaffolds with cells seeded on them were initially fixed with formaldehyde, dried using ethanol and HMDS before sputter coating the samples. The fibers were viewed in the FESEM under varying voltages and magnifications. Image ${ }^{\mathrm{TM}}$ was used for measuring the diameters of the fibers. The directionality tool in the software was used for calculating the deviation of the fibers in the scaffolds.

\subsubsection{Fourier transform Infrared spectroscopy (FTIR)}

Infrared light is radiated on to the samples. The samples absorbed radiation at a point only when the energy equaled to one of the transitions among the discrete energy levels of the molecule. The change is visible only when the molecules also have a net dipole movement. The change in absorbance or the transmittance is used to identify molecules based on the bonds. KBr crystal with Germanium which is used as a beam splitter and a detector to detect the changes in absorbance are the basic components of the FTIR. A spectrum is obtained based on the absorbances of the bonds in the molecules over a range of wavenumbers, typically $400-4000 \mathrm{~cm}^{-1}$. The spectrum is compared with existing spectra to identify the molecules.

The Signal to Noise ratio (SNR) is very high for FTIR. The working parameters are relatively easy and it acts as a quick and efficient method to analyze the nanofibers. It helps in characterizing the phases of the polymer and addition or deletion of bonds between samples at different conditions like temperature. The spectral resolution remains constant throughout the spectral range. Nanograms of sample is enough for analysis and is nondestructive i.e., the samples can be reused after analysis. A small piece of sample was cut 
from the electrospun mat and used for characterization. The spectra were collected in a range between $4000 \mathrm{~cm}^{-1}-400 \mathrm{~cm}^{-1}$ with a scanning resolution of $2 \mathrm{~cm}^{-1}$ and 20 scans for all the samples tested.

\subsubsection{X-Ray Diffraction (XRD)}

The samples are irradiated with X-ray radiation from a source. The interaction of the low wavelength with the samples at an angle is used to find the Miller Indices of the sample using Bragg's law given by the equation:

$$
n \lambda=2 d_{h, k, l} \sin \theta
$$

\section{Equation 1}

Where, $d$ refers to the interplanar distance, $\lambda$ refers to the wavelength of light source used, $\theta$ refers to the angle at which it is reflected and $n$ is an integer. The interplanar distances are dependent on the type of the crystal lattice systems. Based on the theta values obtained for the peaks, the type of material and its phase can be identified by referencing with a database. XRD is an effective method to precisely characterize the crystalline structure. This information can be used to predict or confirm the electrical or mechanical properties of the material. The change in the angles can also be approximated to the formation of new bonds leading to a change in phases of the material. X-Ray Diffraction was used to analyze the samples using a $\mathrm{Cu}-\mathrm{K} \alpha(\lambda=1.5418 \AA)$ as the source of X-ray radiation. The spectrum were obtained in the range between $5^{\circ}-70^{\circ}$.

\subsubsection{Dynamic Mechanical Analysis (DMA)}

The dynamic mechanical analysis is a destructive method for measuring the material's mechanical properties. The specimen of known dimensions is loaded onto the clamp holder apparatus in the DMA. A load is applied to the sample and the strain is measured. There are different methods to control the load-displacement. It can either be controlled by applying a sinusoidal stress and measuring the strain or the load can be increased gradually till fracture point. For measuring the mechanical properties of the scaffolds here, the displacement was varied with time and the stress was obtained, until fracture. The temperature was maintained at $30^{\circ} \mathrm{C}$. 


\subsubsection{Cell seeding experiments}

\subsubsection{Cell seeding}

Rat cardiomyoblasts purchased from ATCC (H9c2(2-1) (ATCC ${ }^{\circ}$ CRL-1446 ${ }^{\mathrm{TM}}$ ), were cultured in Dulbecco's modified eagle medium (DMEM), supplemented with 10\% FBS along with 1\% Pen Strep under standard culture conditions. The cells were passaged per recommended protocol. The scaffolds were cut into squares with length of the side equal to $1 \mathrm{~cm}$ followed by sterilization in $70 \%$ ethanol overnight with UV exposure and then soaking in cell culture media overnight. The culture plates were coated with PDMS $(10: 1)$ to minimize the adhesion of the cells to the bottom of the wells. The scaffolds were transferred to the culture plates and a PDMS ring was used on each fiber to help position the fibers and prevent them from floating away. Approximately, $2 \times 10^{4}$ cells were placed on each scaffold after determining the cell number using a hemocytometer. The culture plates were then left in the incubator for $30 \mathrm{~min}$ to maximize cell adhesion. The fibers were provided with $100 \mu \mathrm{l}$ full media every $30 \mathrm{~min}$ for 2 hours, followed by addition of $3 \mathrm{ml}$ of cell culture media in each well. The cells were placed in an incubator in standard conditions after the initial seeding.

\subsubsection{Characterization post-cell seeding}

The following methods were used for characterization of the scaffolds seeded with cells.

\subsection{Fluorescence microscopy}

The cells seeded on the scaffolds were visualized using immunostaining. Cells were visualized via fluorescence microscopy after 24, 48, 72 hours as well as 168 hours or 7 days of growth. Cells were first washed with PBS. A 16\% methanol-free paraformaldehyde solution (Thermo Scientific, USA) was diluted in PBS to 4\% and was used for cell fixation. Cells were incubated for ten minutes and were then permeabilized in $0.1 \%$ Triton X-100 for 2 min. Samples were then washed with PBS to remove the excessive Triton X-100. Samples were subsequently stained with DAPI (Life Technologies, USA) as well as Alexa 
Fluor® 488 Phalloidin (Life Technologies, USA) for nuclei and cytoskeleton visualization per manufacturer's protocols.

\subsection{FESEM imaging of cell seeded scaffolds}

The samples were fixed and placed in $10 \%$ formalin for at least 30 days at $4{ }^{\circ} \mathrm{C}$. The formalin was removed and washed with PBS three times. The samples are then soaked in PBS for $5 \mathrm{~min}$ for before soaking in ethanol of varying concentrations for drying. Ethanol solutions from $10 \%$ to $100 \%$ were used by increasing the concentration in steps of $10 \%$ in 5 minute intervals. The samples are not allowed to dry out and after washing with $100 \%$ ethanol, the sample was covered in HMDS for 30min. After drying the samples with HMDS, the samples were coated with a $5 \mathrm{~nm}$ thin layer of $\mathrm{Pt} / \mathrm{Pd}$ using a sputter coater as described earlier in section 4.3.1.1. 


\section{Chapter 5: PCL based electrospun scaffolds}

\subsection{Introduction}

PCL, an aliphatic linear polyester is a widely-used polymer in drug delivery and tissue scaffold engineering [77]. It is a biocompatible and biodegradable polymer with a low melting point $\left(55^{\circ} \mathrm{C}-70^{\circ} \mathrm{C}\right)$. The polymerization of PCL is relatively easy, making it inexpensive. The mechanical properties of PCL can be modified based on the requirements of its application. It is FDA approved and has been clinically used for drug delivery applications [78]. PCL is different from other aliphatic polyesters like polyglycolic acid and polylactic acid as it does not have stereoisomers and hence, can be used for many applications. It's compatibility with a wide range of organic solvents makes it a suitable polymer for various applications including electrospinning. PCL has been used with a wide range of synthetic and natural polymers [79].

\subsection{Design of experiments}

Different PCL-based scaffolds were prepared to meet the requirements of a 3D biomimetic scaffold. Different nanofibrous scaffolds were obtained and the most favorable

of them was decided based on the thickness and morphology primarily before any cell seeding experiments.

\subsubsection{Honeycomb shaped scaffold}

\subsubsection{Methods}

The sol-gel for electrospinning was prepared by dissolving $3 \mathrm{~g}$ of PCL in $15 \mathrm{~mL}$ chloroform and $10 \mathrm{~mL}$ methanol to obtain a $12 \%$ PCL solution. The sol-gel was used for electrospinning using a tip collector distance of $6.5 \mathrm{~cm}$, a needle size of $221 / 2 \mathrm{G}$ and an applied voltage of $25 \mathrm{kV}$. The fluid flow was maintained at $1.5 \mathrm{~mL} / \mathrm{min}$. The scaffolds were imaged using FESEM. 


\subsubsection{Results and Discussion}
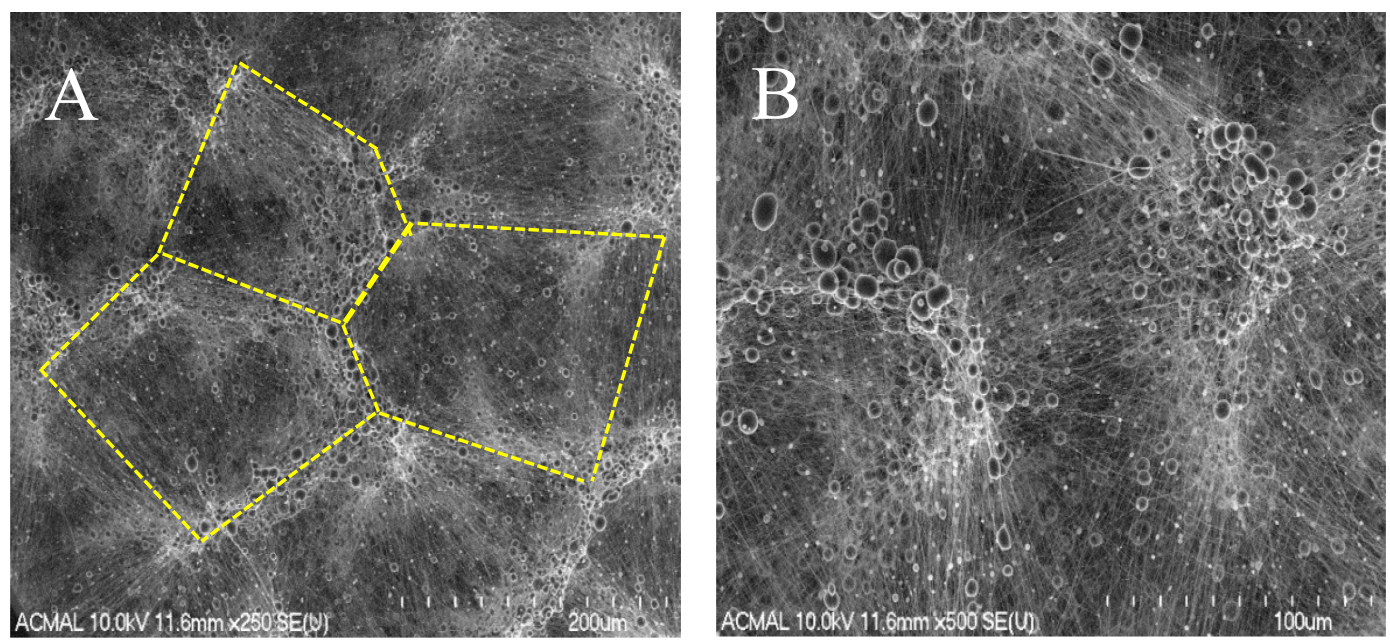

Figure 5.1 shows the FESEM images of the honeycomb shaped scaffold. Figure 5.1 A shows the high magnification image while the lower magnification image is seen in figure 5.1 B. The yellow colored dotted lines in figure 5.1 A highlight the honeycomb structure.

The FESEM images as seen in figure 5.1 show the honeycomb pattern that is obtained. The honeycomb patterns are clearly visible and they are lined with the beads as seen in figure 5.1. The size and shape of the patterns is non-uniform and, due to the presence of beads the fibers had limited thickness and mechanical strength. The patterns are formed because of electrospraying and electrospinning occurring simultaneously due to the high flow rate and low concentration of the polymer. The scaffolds obtained did not have a third dimension necessary for high cell density and hence, they were not the ideal scaffold and no cell seeding experiments were performed on the scaffold.

\subsubsection{Tear shaped scaffold}

\subsubsection{Methods}

A $20 \%$ PCL in chloroform solution was used for electrospinning. An applied voltage of $11.8 \mathrm{kV}$ and a rotating collector speed of 500rpm was used. The polymer flow rate was carefully controlled at $0.75 \mathrm{ml} / \mathrm{hr}$. The scaffolds were imaged using FESEM. 


\subsubsection{Results and discussion}

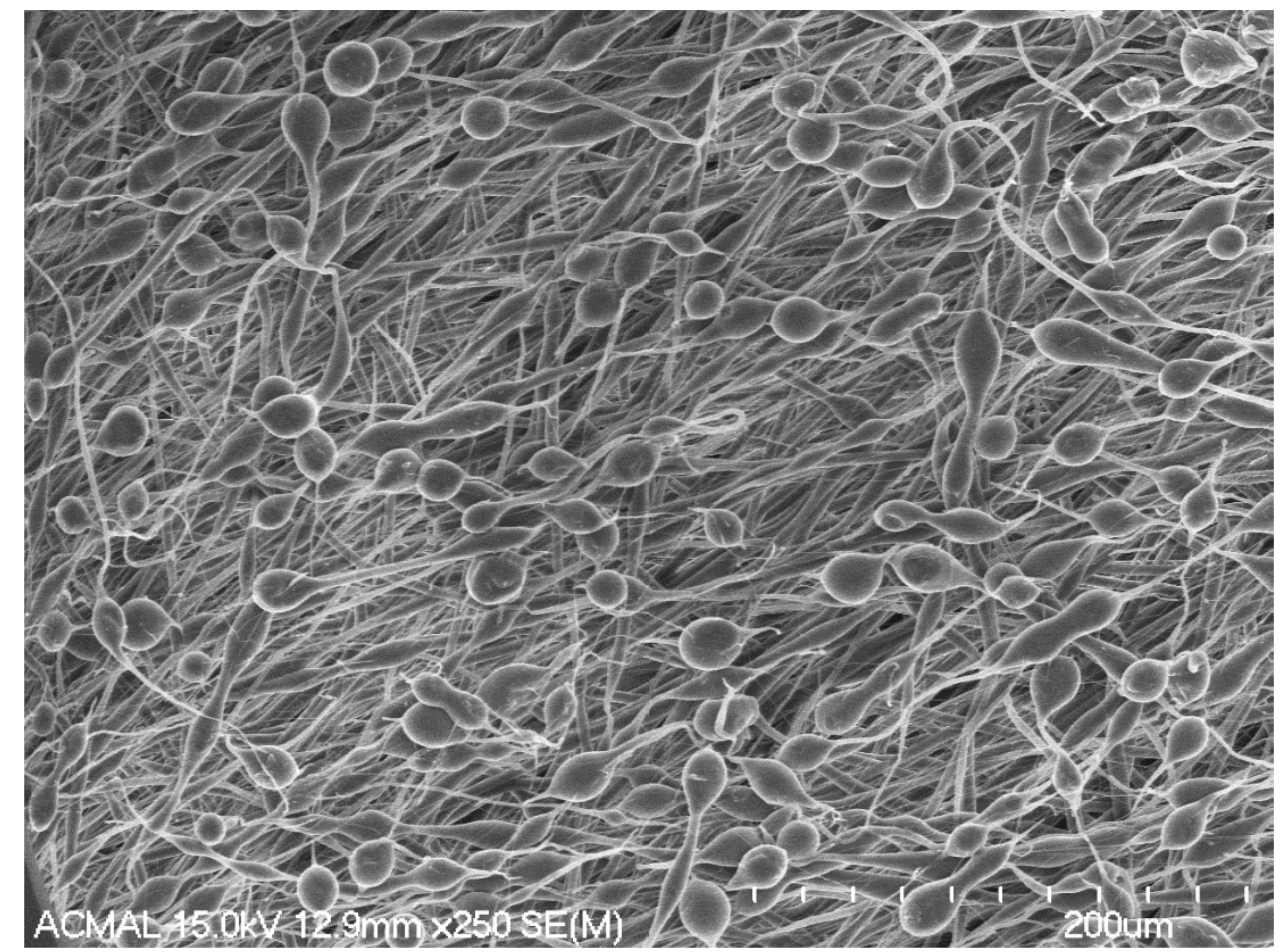

Figure 5.2 shows the FESEM image of the tear shaped scaffold

The scaffolds as seen from the FESEM images in figure 5.2 have a tear shaped structure. There is an underlying orientation to the fibers which can be seen from the lower layers of the tear shaped pattern. The fibers are very dense and have high porosity. The reason for the unique morphology is due to the low voltage and the higher polymer flow rate used. This leads to lower time for polarization of droplets leading to improper splitting of the fibers and deposition of improperly elongated droplets. The fibers are aligned because the rotating collector speed is approximately equal to the critical uptake velocity. The scaffold obtained here has a unique morphology but the requirements for a biomimetic scaffold (as discussed in section 1.3) is not met and hence, cell seeding was not performed on the scaffold. 


\subsubsection{Aligned scaffold}

\subsubsection{Methods}

A $20 \%$ PCL in chloroform solution was used for electrospinning. An applied voltage of $14 \mathrm{kV}$ and a rotating collector speed of $400 \mathrm{rpm}$ was used. The polymer flow rate was carefully controlled at $80 \mu \mathrm{l} / \mathrm{hr}$.

\subsubsection{Results and discussion}

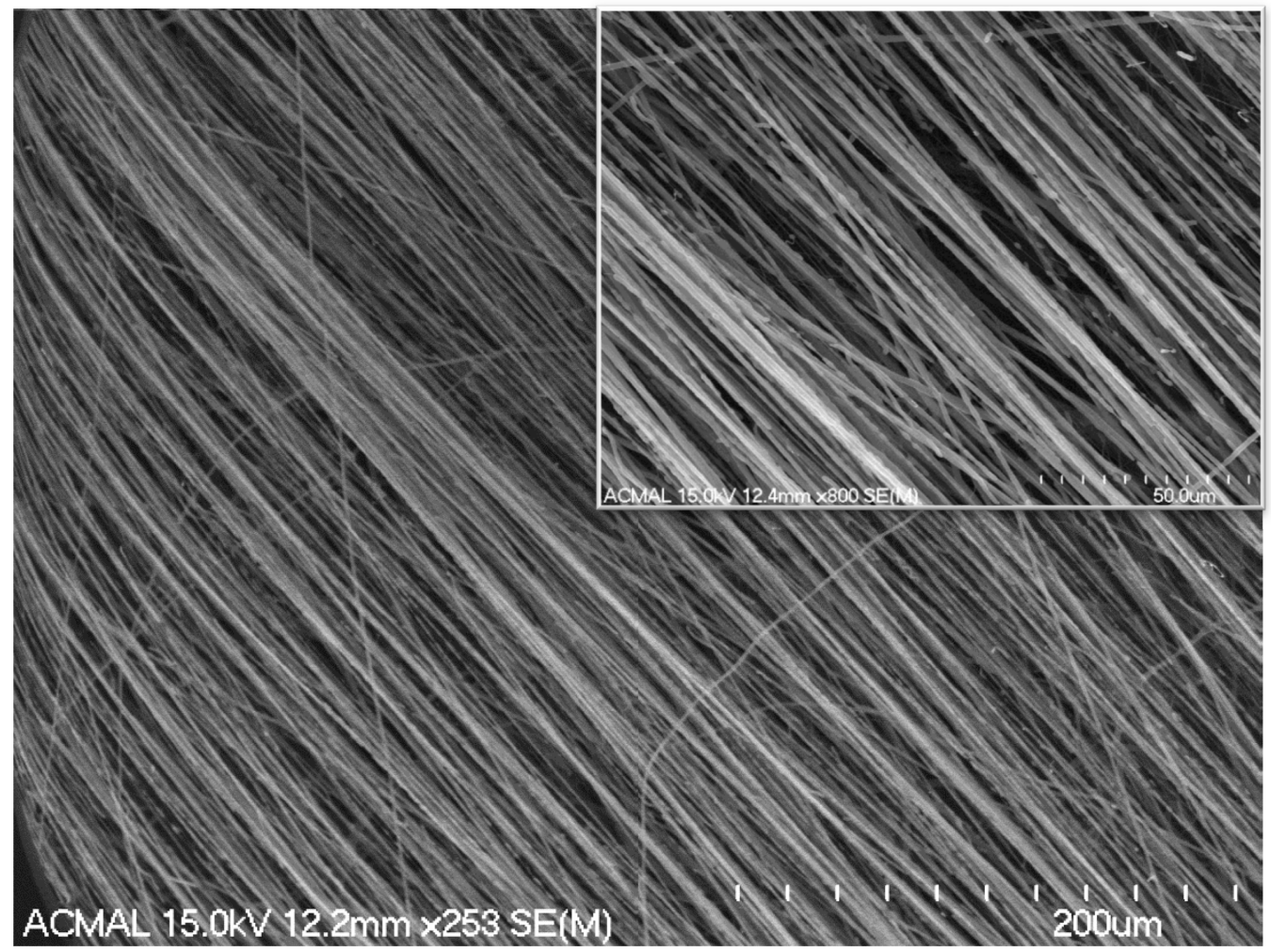

Figure 5.3 shows the FESEM images of the aligned scaffold. The inset shows the high magnification of the aligned fibers.

The FESEM images of the scaffold can be seen from figure 5.3. The fibers are aligned and oriented uniformly. The surface of the fibers is covered with ridges (as seen from the inset from figure 5.3) on them which can facilitate cell adhesion by increasing the surface area. There are certain deviations in the alignment which is expected because of splaying. The rotational velocity used here is equal to the critical uptake velocity. The 
density of the fibers in the scaffold is low because of which it cannot be used as 3D tissue scaffold.

\subsubsection{D scaffold}

\subsubsection{Methods}

A $20 \%$ PCL in chloroform solution was used for electrospinning. An applied voltage of $12 \mathrm{kV}$ and a rotating collector speed of $400 \mathrm{rpm}$ was used. The polymer flow rate was carefully controlled at $25 \mu \mathrm{l} / \mathrm{min}$. The scaffolds are characterized using FESEM, XRD, DMA and FTIR. Scaffolds are seeded with cells and the interactions are used for designing better scaffolds.

\subsubsection{Results and discussion}

\subsection{FESEM}

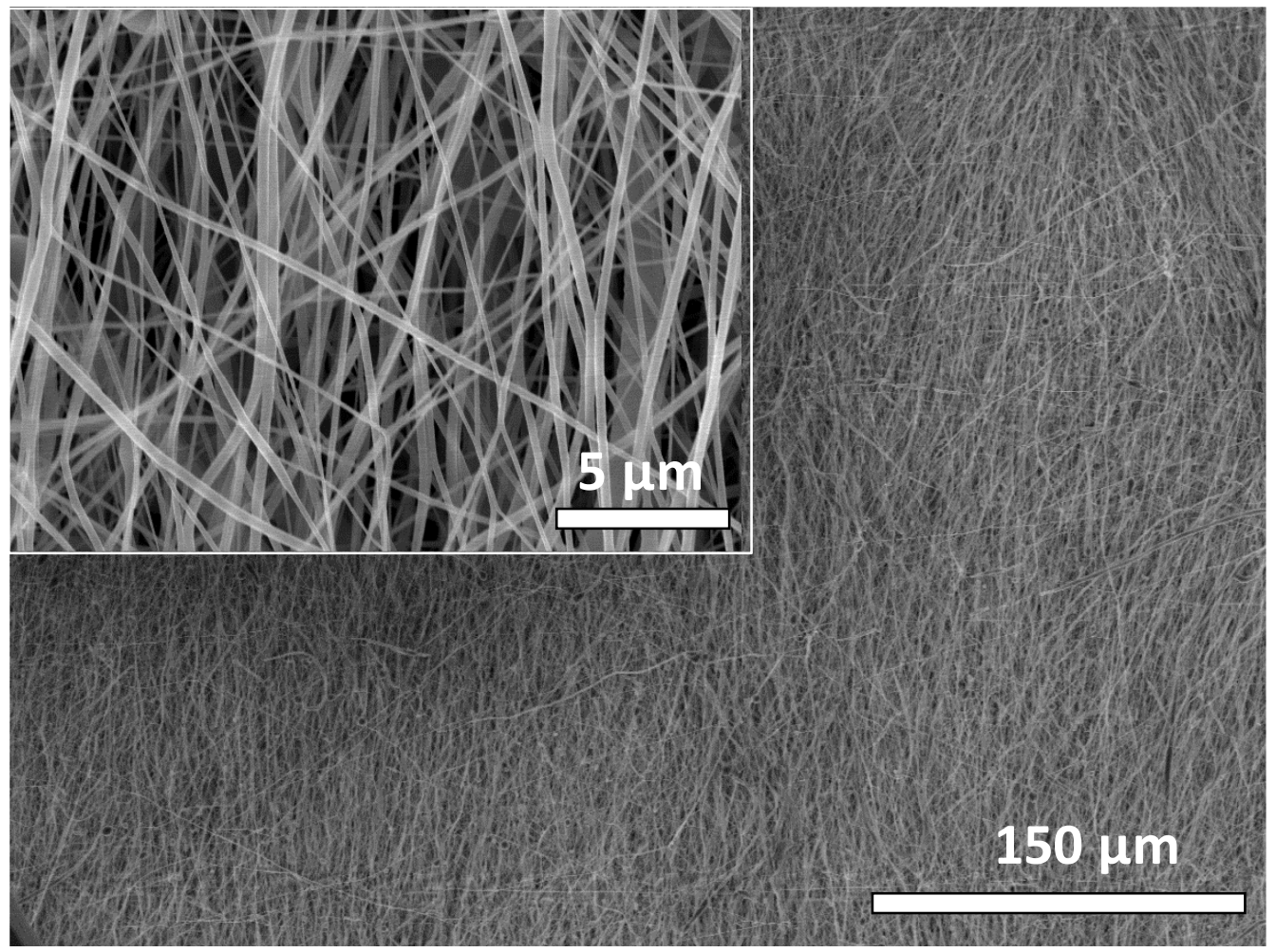

Figure 5.4 shows the FESEM images of the 3D scaffold. The inset shows the magnified image of the scaffold. 
Visualizing the fibers under the FESEM showed the formation of aligned PCL nanofibers throughout the sample. The average diameter of the fibers were $280 \mathrm{~nm}$ with a standard deviation around $60 \mathrm{~nm}$ which was measured from the inset in figure 5.4. The alignment of the fibers calculated had a low deviation of $17.46^{0}$. The fibers had certain regions of non-alignment. This was caused because of clogs formed during electrospinning. Chloroform, which was used as a solvent for the preparation of PCL solution has a high intrinsic viscosity and low boiling point. The high intrinsic viscosity was favorable for fabrication of continuous fibers without any beading.

\subsection{FTIR}

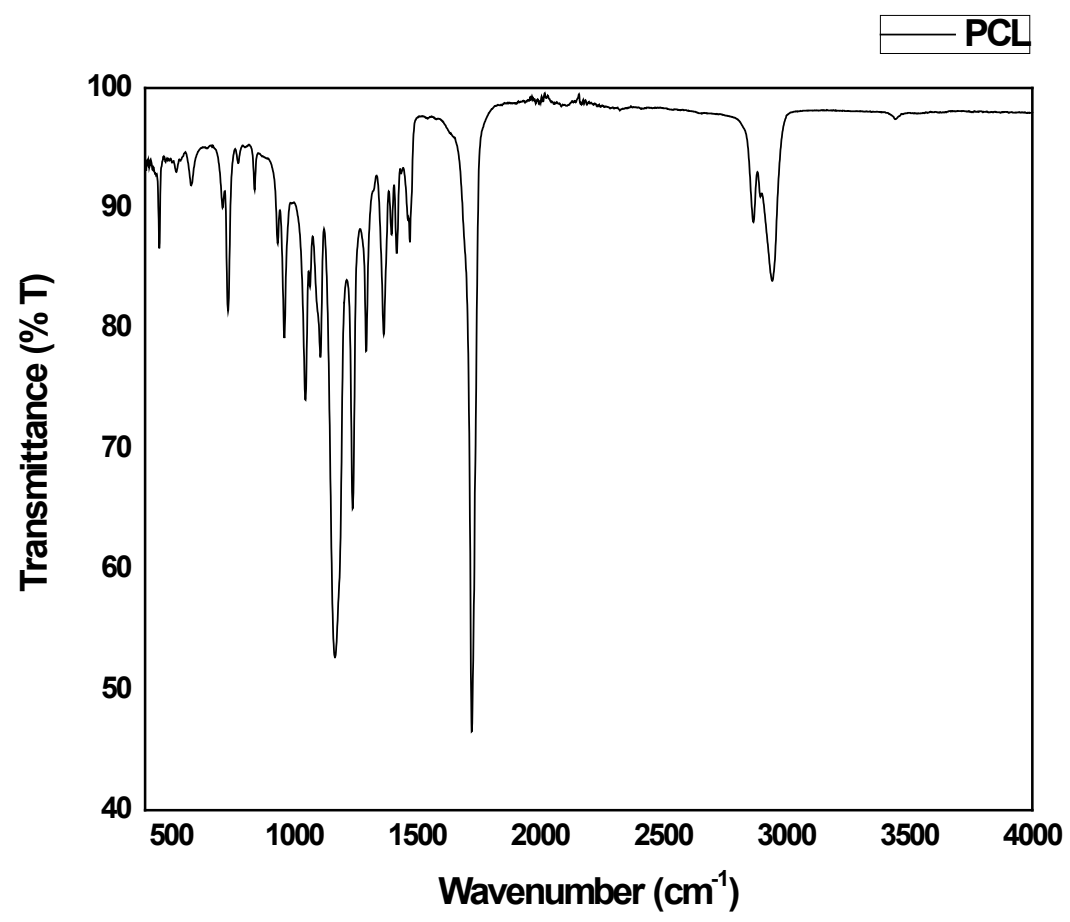

Figure 5.5 shows the FTIR spectrum of the 3D scaffold from a region of $400 \mathrm{~cm}^{-1}$ to $4000 \mathrm{~cm}^{-1}$. 
Table 5.1: A list of all the major peaks from FTIR spectrum and the description of the vibrations

\begin{tabular}{|c|c|}
\hline Wavenumbers (cm-1) & Description of vibrations \\
\hline 1722 & $\mathrm{C}=\mathrm{O}$ stretching \\
\hline $1471,1397,1364$ & $\mathrm{CH}_{2}$ bending \\
\hline $\begin{array}{c}2944 \text { (asymmetric), } 2866 \\
\text { (symmetric) }\end{array}$ & $\mathrm{CH}_{2}$ stretching \\
\hline $1238,1107,1046$ & $\mathrm{C}-\mathrm{O}-\mathrm{C}$ stretching \\
\hline 1166 & $\mathrm{C}-\mathrm{O}$ stretching \\
\hline 1293 & $\begin{array}{c}\mathrm{C}-\mathrm{O} \text { and } \mathrm{C}-\mathrm{C} \text { stretching in the } \\
\text { crystalline phase }\end{array}$ \\
\hline 582 & $\mathrm{C}=\mathrm{O}$ wag \\
\hline
\end{tabular}

ATR-FTIR was used for analyzing the surface functional groups of the scaffold. Table 5.1 lists all the significant peaks from the spectrum which is shown in figure 5.5. The characteristic peaks of PCL such as the $\mathrm{C}=\mathrm{C}, \mathrm{C}=\mathrm{O}$ are present. The strong intensity peaks at $1722 \mathrm{~cm}^{-1}\left(\mathrm{C}=\mathrm{O}\right.$ stretching) and $1166 \mathrm{~cm}^{-1}$ (C-O stretching), and medium intensity peaks at $2944 \mathrm{~cm}^{-1}$ (asymmetric $\mathrm{CH}_{2}$ stretching) and $2866 \mathrm{~cm}^{-1}$ (symmetric $\mathrm{CH}_{2}$ stretching) were unique to PCL. The weak intensity peak at $582 \mathrm{~cm}^{-1}$ is specific to the $\mathrm{C}=\mathrm{O}$ wag in PCL. The strong intensity peak at $1293 \mathrm{~cm}^{-1}$ is specific to the C-O and C-C stretching in the crystalline phase of PCL. This crystalline phase is expected because of the high electric field during fabrication which causes the $\mathrm{C}-\mathrm{O}$ bonds to be oriented. The change in molecular orientation affects the mechanical properties of the scaffold. 


\subsection{XRD}

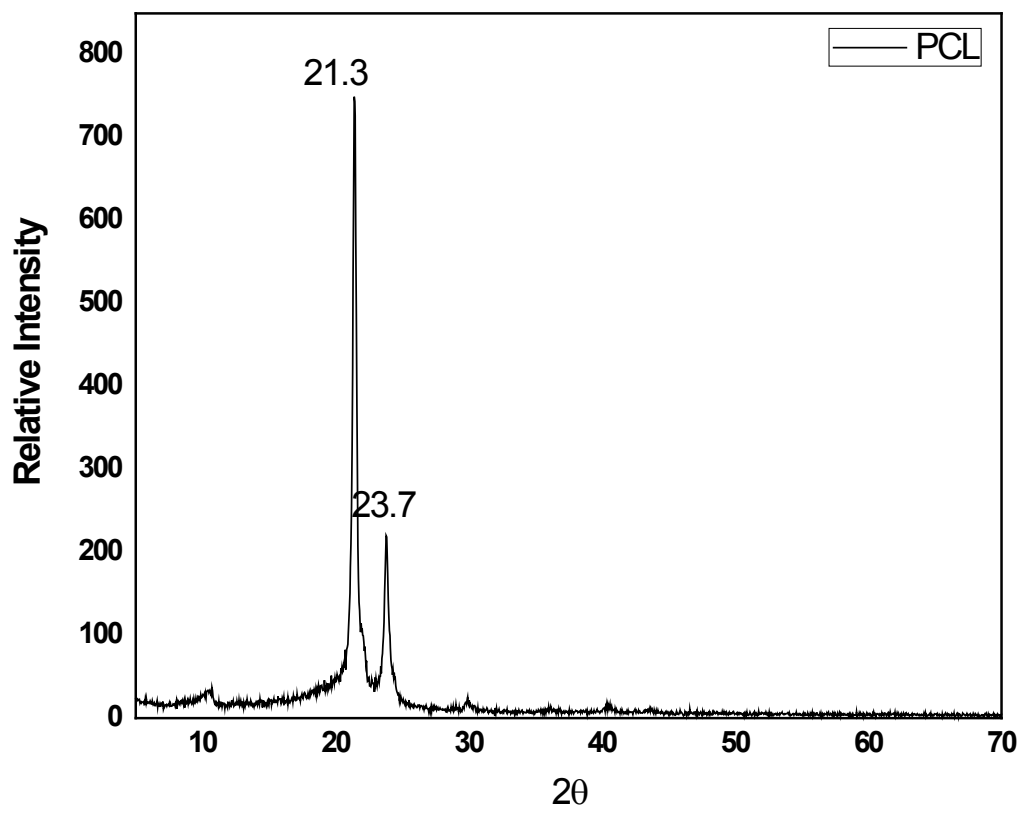

Figure 5.6 shows the powder XRD spectrum of the 3D scaffold.

The crystalline nature of PCL is evident from the narrow peaks from the XRD spectrum seen in figure 5.6. The peaks at $21.30^{\circ}$ and $23.70^{\circ}$ have a d-spacing of $4.15 \AA$ and $3.73 \AA$ respectively. The degree of crystallinity of PCL was found to be 0.6452 . The peaks were indexed to (110) and (200) lattice planes of the orthorhombic unit cell. 


\subsection{DMA}

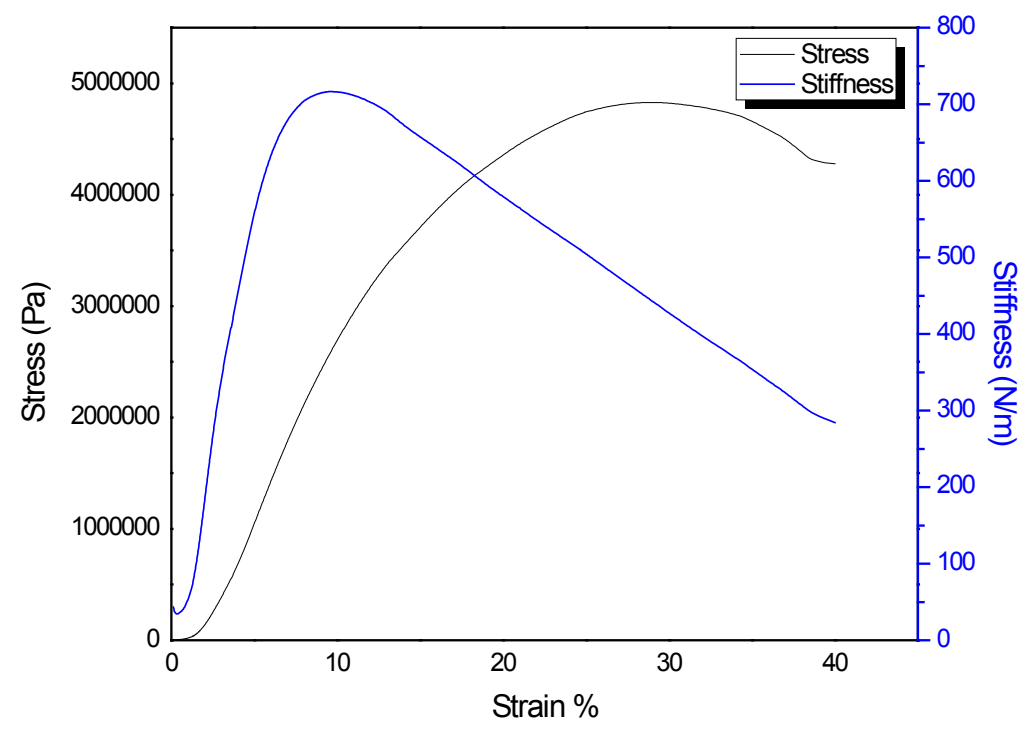

Figure 5.7 shows the stress-strain-stiffness plot of the 3D scaffold.

Table 5.2: The mechanical properties of the 3D scaffold calculated from the stress-strainstiffness plot.

\begin{tabular}{|c|c|}
\hline Young's Modulus & $0.31 \mathrm{MPa}$ \\
\hline Ultimate Tensile Strength & $4.83 \mathrm{MPa}$ \\
\hline Elongation at Fracture & $40.00 \%$ \\
\hline Modulus of Toughness & $140.81 \mathrm{MPa}$ \\
\hline
\end{tabular}

The mechanical properties, such as the Young's Modulus, ultimate tensile strength and the elongation at fracture of the three polymers were characterized from the stressstrain graph as seen in figure 5.7 and tabulated in table 5.2. PCL displays the behavior of a typical elastic polymer with a very significant change in strain with small amounts of stress. The mechanical properties of PCL can be correlated with the crystallinity of the scaffold. The higher degree of crystallinity leads to lesser disorder in the system thus increasing the mechanical properties. 


\subsection{Cell seeding experiments}

\subsection{Fluorescence microscopy}
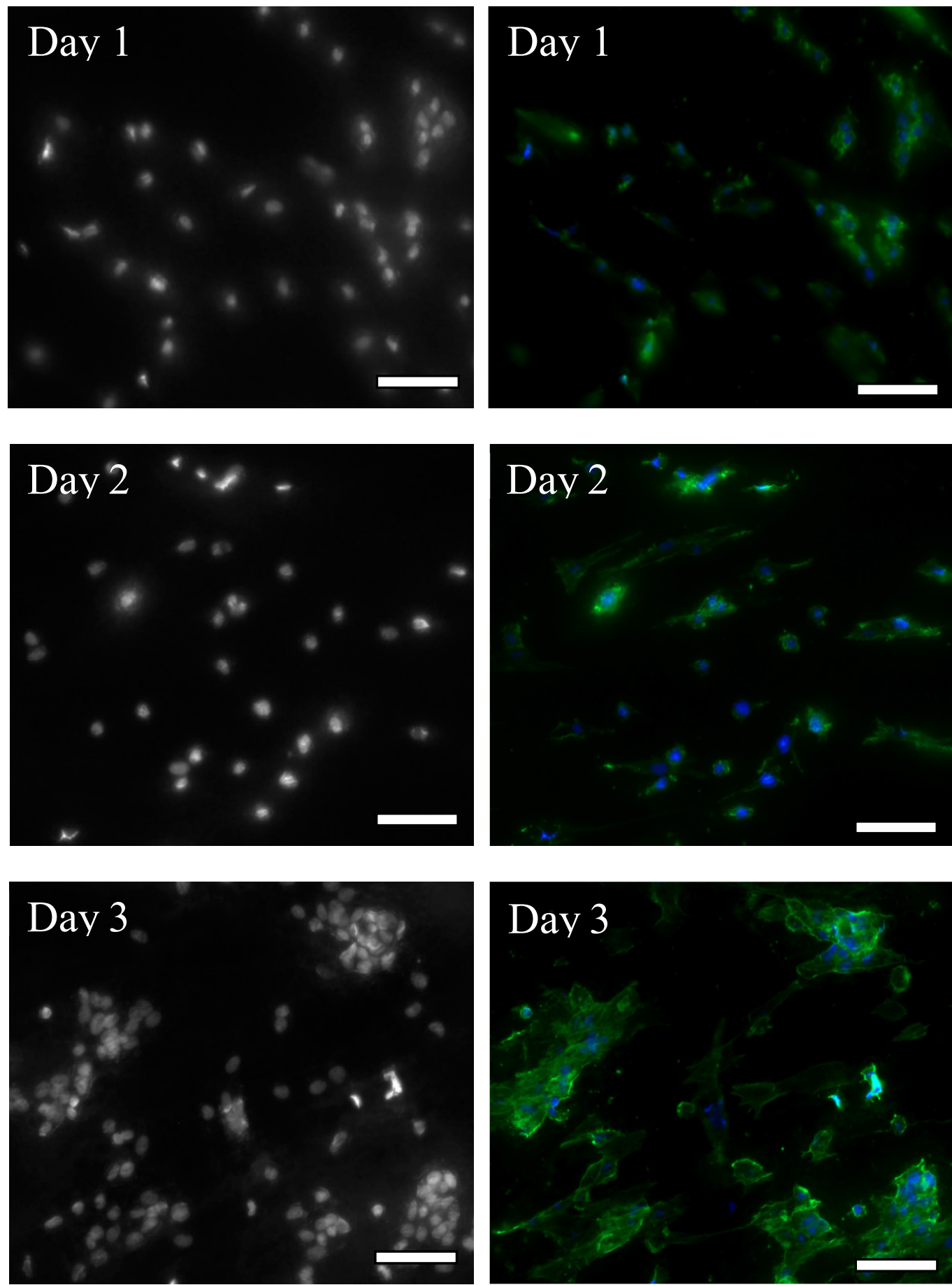

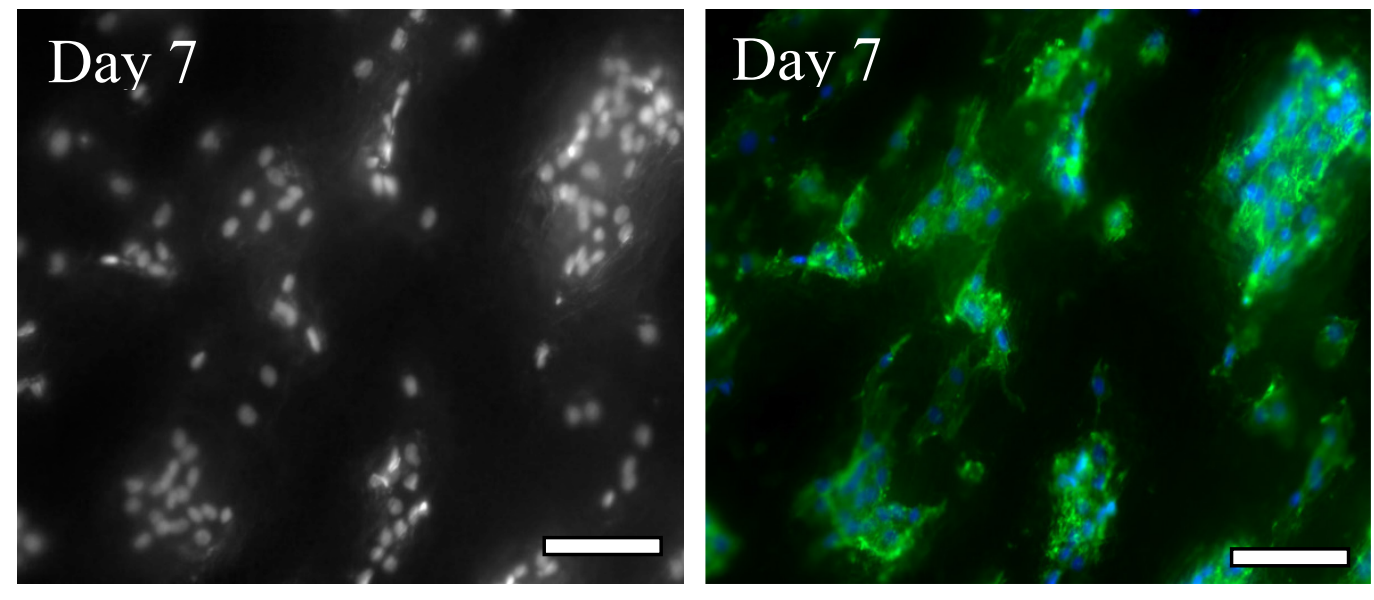

Figure 5.8 shows the cells seeded on the scaffolds after immunofluorescent staining on days 1, 2, 3 and 7. The images on the left column show the DAPI stained cells while the images on the right show the cells stained with DAPI and Alexa Fluor. The blue color (DAPI) represents the nucleus and the green color (Alexa Fluor) represents the actin filaments.

The nanofibers after cell seeding were fixed and stained with DAPI and Alexa Fluor ${ }^{\circledR} 488$ Phalloidin to visualize the nucleus and the actin filaments as seen in figure 5.8. The cells did not spread evenly through the PCL scaffold and the cells were clumped in regions. The actin filaments were not present throughout the scaffolds and the nucleus were round. 


\subsection{FESEM imaging of cell seeded scaffolds}
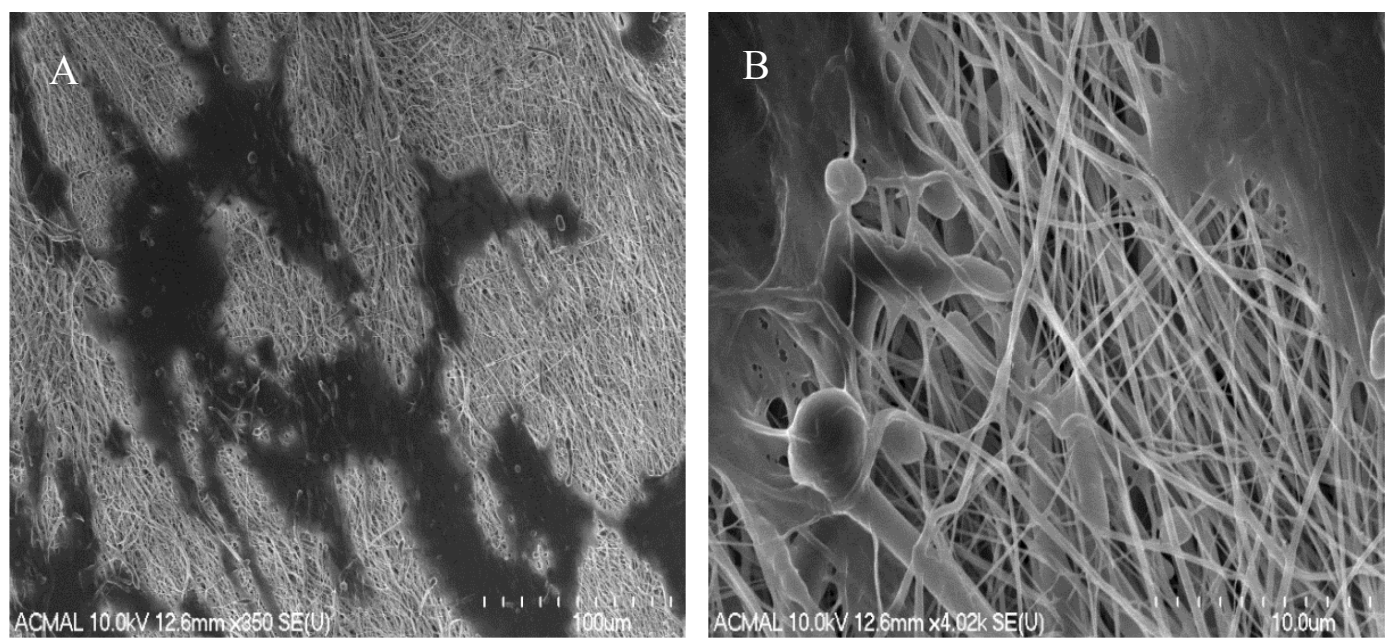

Figure 5.9 shows the FESEM image of the scaffold after cell seeding. The cells were fixed after day 3 and imaged. Figure 5.9 A shows a low magnification image and figure

5.9 B shows a high magnification image of the scaffold seeded with cells.

The FESEM images of PCL as seen in figure 5.9 help in identifying the behavior of the cells on the scaffolds. The cells on PCL scaffolds had no penetration and the cells clumped together indicating little cell migration and alignment. The cellular penetration, cell migration on scaffold and cellular alignment are one of the standard characteristic features by which the scaffold's likeliness to a natural scaffold is compared. PCL has very poor cellular attachment, proliferation and migration which makes it an unsuitable scaffold despite its high elastic modulus and localized alignment of fibers. 


\subsection{Conclusions}

Table 5.3 summarizes the different PCL based scaffolds

\begin{tabular}{|c|c|c|c|}
\hline Type of scaffold & Morphology & Hypothesis \\
shaped scaffold & $\begin{array}{c}\text { Honeycomb } \\
\text { patterns were } \\
\text { fabricated without } \\
\text { any modifications } \\
\text { to the substrate }\end{array}$ & $\begin{array}{c}\text { The honeycomb } \\
\text { pattern might } \\
\text { provide the } \\
\text { required porosity } \\
\text { for scaffold } \\
\text { infiltration. }\end{array}$ & $\begin{array}{c}\text { Challenges faced } \\
\text { droplets prevented } \\
\text { a high mechanical } \\
\text { strength or } \\
\text { increased density } \\
\text { of the scaffold }\end{array}$ \\
\hline $\begin{array}{c}\text { Tear shaped } \\
\text { scaffold }\end{array}$ & $\begin{array}{c}\text { Aligned and dense } \\
\text { fibers with } \\
\text { elongated beads }\end{array}$ & $\begin{array}{c}\text { The unique } \\
\text { morphology might } \\
\text { provide necessary } \\
\text { surface area and } \\
\text { porosity }\end{array}$ & $\begin{array}{c}\text { The thickness of } \\
\text { the fibers was } \\
\text { limited because of } \\
\text { the formation of } \\
\text { beads }\end{array}$ \\
\hline Aligned scaffold & $\begin{array}{c}\text { Aligned fibers with } \\
\text { wedges on the } \\
\text { surface }\end{array}$ & $\begin{array}{c}\text { The wedges on the } \\
\text { surface might } \\
\text { provide the } \\
\text { necessary surface } \\
\text { area and increase } \\
\text { cellular alignment }\end{array}$ & $\begin{array}{c}\text { The use of volatile } \\
\text { solvents prevented } \\
\text { the continuous } \\
\text { deposition of } \\
\text { nanofibers }\end{array}$ \\
\hline 3D scaffold & $\begin{array}{c}\text { Thick dense } \\
\text { scaffold with } \\
\text { aligned fibers }\end{array}$ & $\begin{array}{c}\text { The thickness and } \\
\text { porosity might help } \\
\text { in scaffold } \\
\text { infiltration and } \\
\text { high cell density }\end{array}$ & $\begin{array}{c}\text { Cellular alignment } \\
\text { and scaffold } \\
\text { infiltration was } \\
\text { absent }\end{array}$ \\
\hline
\end{tabular}

Table 5.3 summarizes the different scaffolds that were fabricated and the challenges faced with the scaffolds. The common problem faced by the scaffolds are lack of cellular alignment, scaffold infiltration and localized clumping of the cells. Due to this, the material used for electrospinning needs to be modified to introduce strong permanent polarization in the scaffold. 


\section{Chapter 6: PCL-PVDF based scaffolds}

\subsection{Introduction}

In the case of PCL, there was a lack of cell migration and cellular infiltration. There was also no visible cellular alignment despite the alignment of the fiber structures. Thus, it was hypothesized that by incorporating an electroactive polymer, the alignment and penetration of the cells in the scaffolds could be improved. A combination of PCL and electroactive polymers have been used previously for designing scaffolds as reviewed by Balint et al.[80].

\subsubsection{Polyvinylidene Fluoride (PVDF)}

Polyvinylidene Fluoride or PVDF is a piezoelectric polymer that is biocompatible and non-biodegradable. It has a very high dipole moment. It has been used along with trifluroethylene to increase its piezoelectricity [81]. PVDF has been used for various biomedical applications like fabricating sutures, self-powering devices [82]. The net dipole moment of the bonds contributes to the piezoelectricity of PVDF. The $\alpha$-phase of PVDF has no net dipole moment and hence is not preferred. The $\beta$-phase of PVDF has the highest net dipole moment and is preferred. Electrical poling and mechanical stretching are some of the methods by which the concentration of $\beta$-phase can be increased.

Different concentrations were blended to increase quantity of PVDF to improve the piezoelectric activity in the final nanofibers. However, blends of PCL-PVDF are soluble only with low amounts of PVDF [83]. Thus, in order to increase the quantity of the PVDF polymer in the scaffold, coaxial electrospinning was used for fabrication.

\subsection{Methods}

A coaxial nozzle was used for electrospinning the PCL-PVDF scaffolds. A $20 \%$ PVDF was prepared by dissolving $2 \mathrm{~g}$ PVDF $(\mathrm{Mn}=534,000)$ in $7 \mathrm{~mL}$ DMF and $3 \mathrm{~mL}$ acetone used for the core solution while a 20\% PCL was prepared by dissolving $2 \mathrm{~g}$ PCL in $10 \mathrm{~mL}$ chloroform was used for the sheath solution. An applied voltage of $20 \mathrm{kV}$ across a rotating 
collector (2000rpm) was used with the core and sheath polymer flow rate controlled at $4 \mu \mathrm{l} / \mathrm{min}$ and $2 \mu \mathrm{l} / \mathrm{min}$.

\subsection{Results and discussion}

\subsubsection{FESEM}

The PCL-PVDF fibers as seen in figure 6.1 were semi-aligned. The fibers had an average diameter around $500 \mathrm{~nm}$ with a deviation around $300 \mathrm{~nm}$ which was measured from the inset in figure 6.1. Fibers with diameter as small as $150 \mathrm{~nm}$ and diameter as large as $1000 \mathrm{~nm}$ were present. The alignment of the fibers had a deviation of $27.03^{\circ}$. The partial alignment of the fibers can be attributed to the differential uptake velocities of the polymers. The polymers are immiscible and hence increase instability at the tip leading to jet splitting. Coalescing of the jets is prevented which leads to different diameters of the fibers.

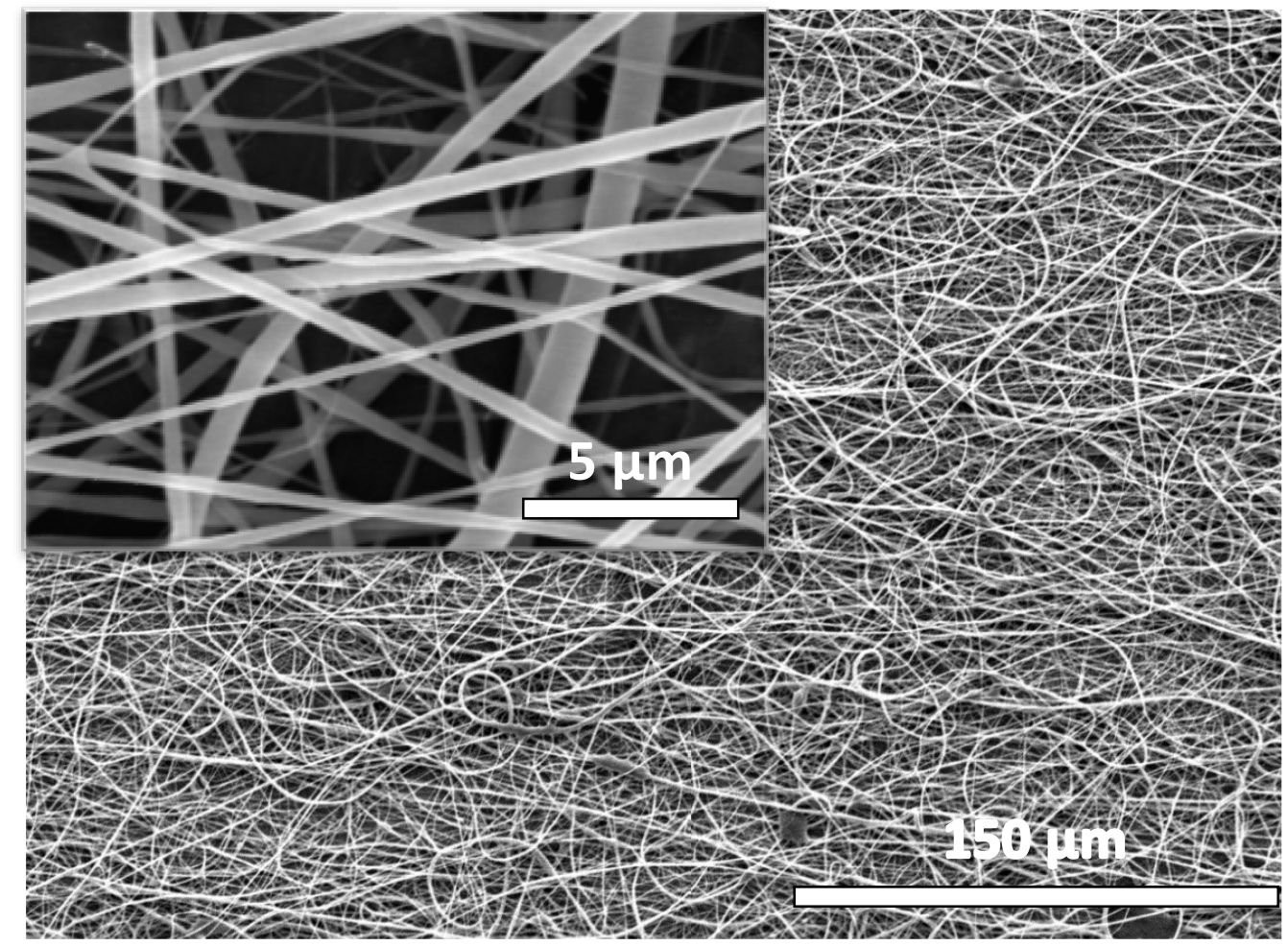

Figure 6.1 shows the FESEM images of the PCL-PVDF scaffold. 


\subsubsection{FTIR}

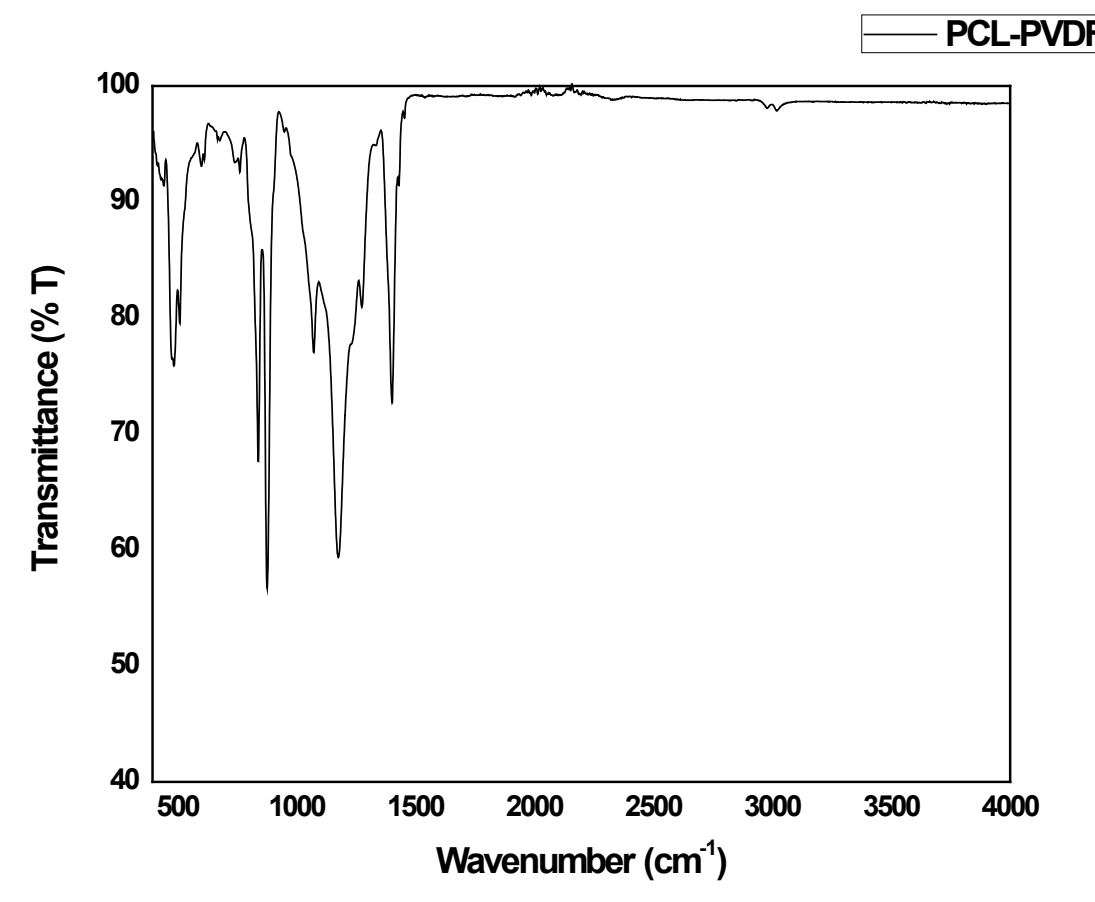

Figure 6.2 represents the FTIR spectrum of the PCL-PVDF scaffold.

Table 6.1: A list of all the major peaks corresponding to PVDF from the FTIR spectrum with a description of the vibrations and the electroactive phase

\begin{tabular}{|c|c|c|}
\hline Description of vibrations & Wavenumbers $\left(\mathrm{cm}^{-1}\right)$ & Electroactive Phase \\
\hline $\begin{array}{c}\text { C-F out-of-plane } \\
\text { deformation }\end{array}$ & 1275 & $\beta$ \\
\hline $\mathrm{CH}_{2}$ rocking & 840 & $\beta$ \\
\hline $\mathrm{CF}_{2}$ bending & 510 & - \\
\hline $\mathrm{CH}_{2}$ symmetric stretching & 3020 & - \\
\hline $\mathrm{CH}_{2}$ asymmetric stretching & 2978 & - \\
\hline $\mathrm{CH}_{2}$ wagging vibration & 1403 & $\beta$ \\
\hline
\end{tabular}




\begin{tabular}{|c|c|c|}
\hline $\begin{array}{c}\mathrm{CF}_{2} \text { bending and scelete } \\
\text { bending }\end{array}$ & 762 & $\alpha$ \\
\hline $\mathrm{CH}_{2}$ rocking & 781 & $\gamma$ \\
\hline
\end{tabular}

Table 6.2: A list of all the major peaks from FTIR spectrum corresponding to PCL

\begin{tabular}{|c|c|}
\hline Description of vibrations & Wavenumbers $\left(\mathrm{cm}^{-1}\right)$ \\
\hline $\mathrm{CH}_{2}$ bending & 1467,1354 \\
\hline Asymmetric $\mathrm{C}-\mathrm{O}-\mathrm{C}$ stretching & 1231 \\
\hline $\mathrm{C}-\mathrm{O}$ stretching & 1176 \\
\hline
\end{tabular}

The PCL-PVDF spectrum showed characteristic high intensity peaks of the $\beta$-phase of PVDF and PCL as seen in figure 6.2 and tabulated in table 6.1 and table 6.2. The high intensity peaks at $840 \mathrm{~cm}^{-1}\left(\mathrm{CH}_{2}\right.$ rocking $)$ can be attributed to both the $\gamma$ as well as the $\beta$ phase of PVDF. However, the strong peaks at $1275 \mathrm{~cm}^{-1}$ (C-F out of plane deformation) and $510 \mathrm{~cm}^{-1}$ ( $\mathrm{CF}_{2}$ bending) corresponds specifically to the $\beta$-phase of PVDF. The characteristic peaks of $\alpha$ and $\gamma$ phases of PVDF are also present at $762 \mathrm{~cm}^{-1}$ (CF2 bending and scelete bending) and $781 \mathrm{~cm}^{-1}\left(\mathrm{CH}_{2}\right.$ rocking) at low intensities [84, 85]. The characteristic peaks of PCL at $1231 \mathrm{~cm}^{-1}$ (asymmetric C-O-C stretching) and $1176 \mathrm{~cm}^{-1}$ (C-O stretching) confirm the presence of PCL in the PCL-PVDF sample. The presence of PVDF alters the type of bonds present and the signature bonds corresponding to the $\mathrm{CH}_{2}$ stretching is absent. The $\beta$-phase of PVDF in PCL-PVDF is at a higher concentration in comparison to the other electroactive forms of PVDF. This is due to the high electric field under which the fabrication of the fibers occur which annuls the need for post-processing by stretching or electric poling to increase concentration of the $\beta$-phase of PVDF [86]. 


\subsubsection{XRD}

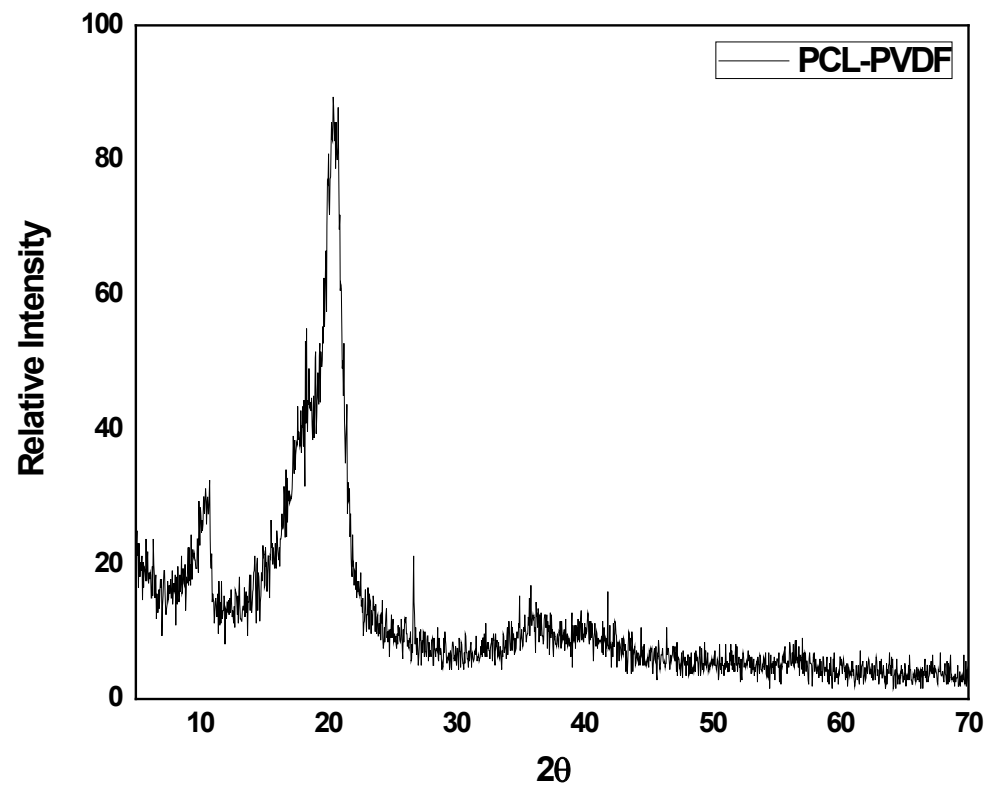

Figure 6.3 shows the XRD spectrum of the PCL-PVDF scaffold

The spectra from PCL-PVDF as seen in figure 6.3 showed no major peaks and the percentage degree of crystallinity was calculated to be $0.21 \%$. The reduced intensities and amorphous behavior is caused due to the lack of local alignment in the samples which leads to lower symmetry in the unit cell. The reduced crystallinity affects the piezoelectricity and the mechanical properties of the polymer scaffold despite the higher concentration of $\beta$ phase of PVDF. 


\subsubsection{DMA}

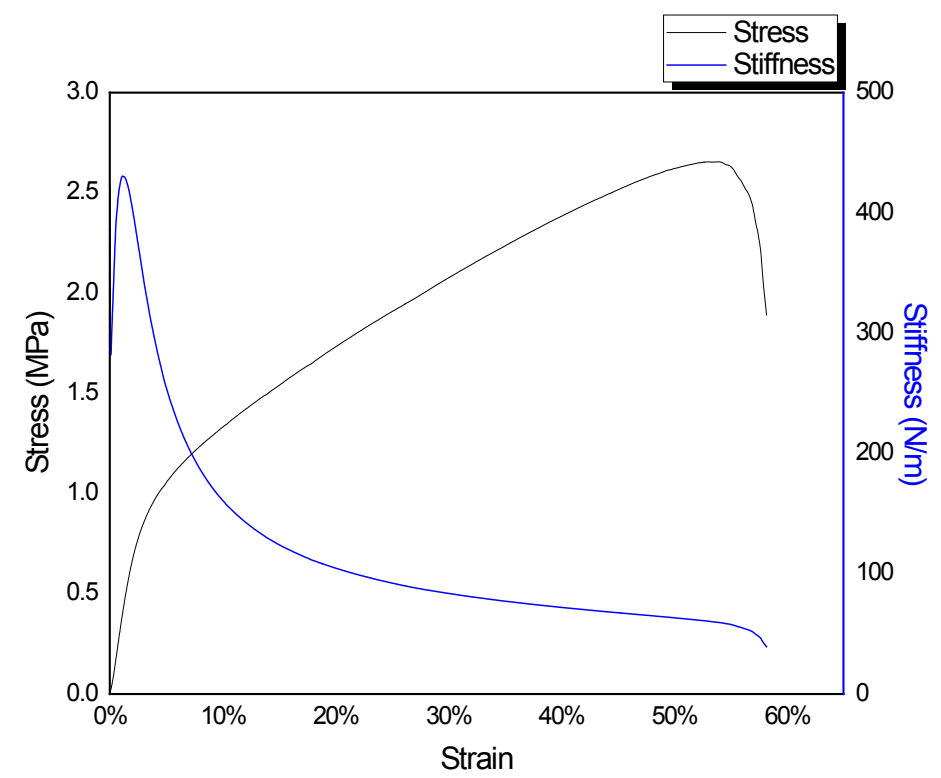

Figure 6.4 represents the stress- strain-stiffness plot of the PCL-PVDF scaffold

Table 6.3: The mechanical properties of the PCL-PVDF scaffold calculated from the stress-strain-stiffness plot.

\begin{tabular}{|c|c|}
\hline Young's Modulus & $0.37 \mathrm{MPa}$ \\
\hline Ultimate Tensile Strength & $2.66 \mathrm{MPa}$ \\
\hline Elongation at Fracture (\%) & $58.19 \%$ \\
\hline Modulus of Toughness & $112.22 \mathrm{MPa}$ \\
\hline Modulus of resilience & $0.93 \mathrm{MPa}$ \\
\hline
\end{tabular}

The stress-strain-stiffness plot of the PCL-PVDF scaffold as seen in figure 6.4 shows the behavior of a glassy polymer with a very large plastic region. The mechanical properties are calculated and tabulated in table 6.3. The plastic region of PCL-PVDF extends beyond the rupture point of PCL scaffold. The loss of alignment affects the mechanical properties of the scaffold making the electrospun scaffold very ductile. 


\subsubsection{Cell seeding experiments}

6.3.5.1 Fluorescence microscopy
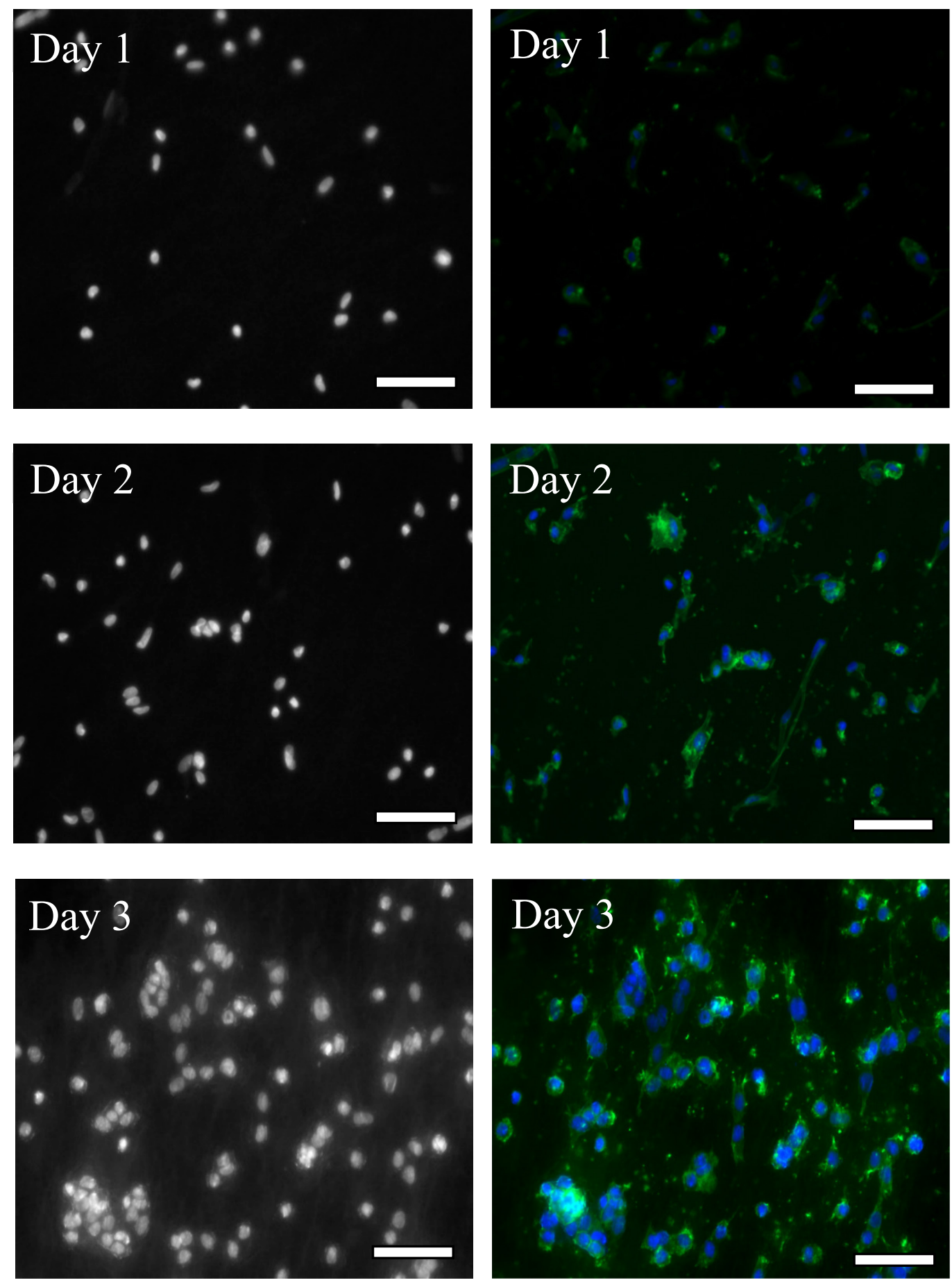

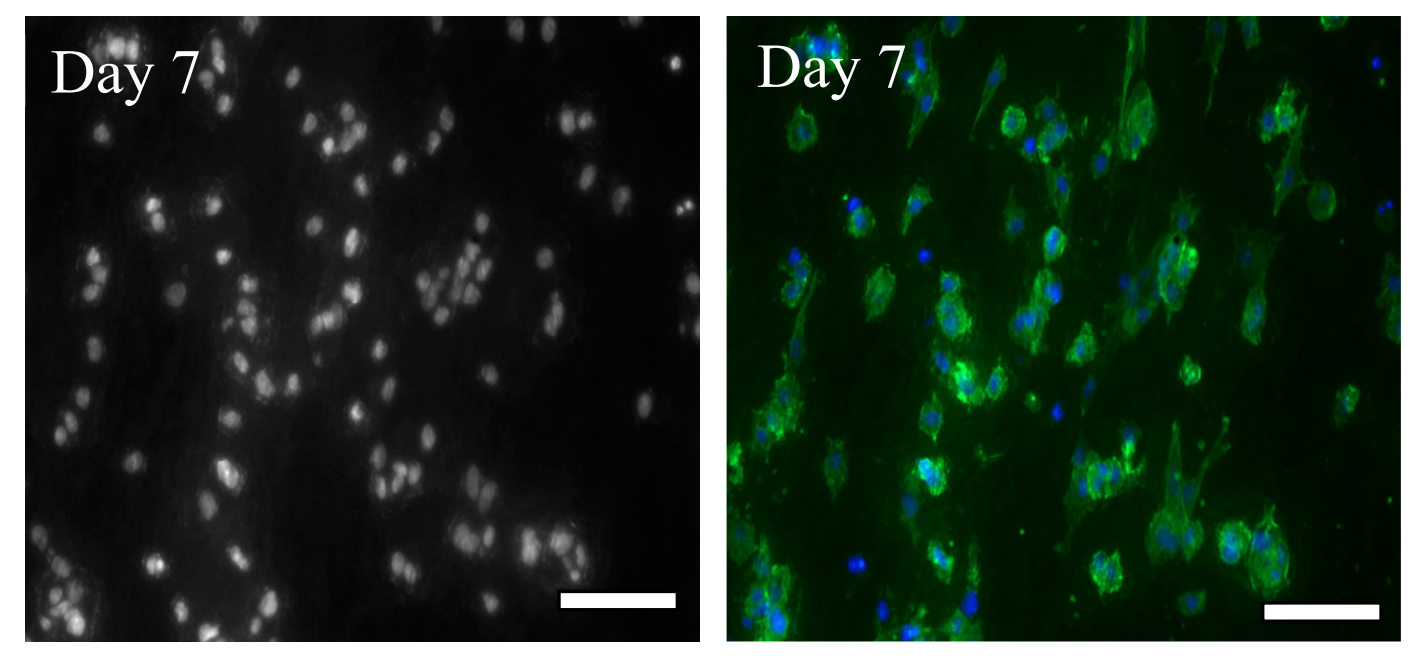

Figure 6.5 shows the cells seeded on the scaffolds after immunofluorescent staining on days 1, 2, 3 and 7. The images on the left column show the DAPI stained cells while the images on the right show the cells stained with DAPI and Alexa Fluor. The blue color (DAPI) represents the nucleus and the green color (Alexa Fluor) represents the actin filaments.

The nanofibers after cell seeding were fixed and stained with DAPI and Alexa Fluor® 488 Phalloidin to visualize the nucleus and the actin filaments. The fibers had some alignment and migration on the scaffold. There was clumping of the cells in some regions of the scaffold and localized alignment of the cells. The shape of the nucleus was elliptical in regions where there is alignment of the cells and rounded in regions where there was clumping. 


\subsubsection{FESEM imaging of cell seeded scaffolds}
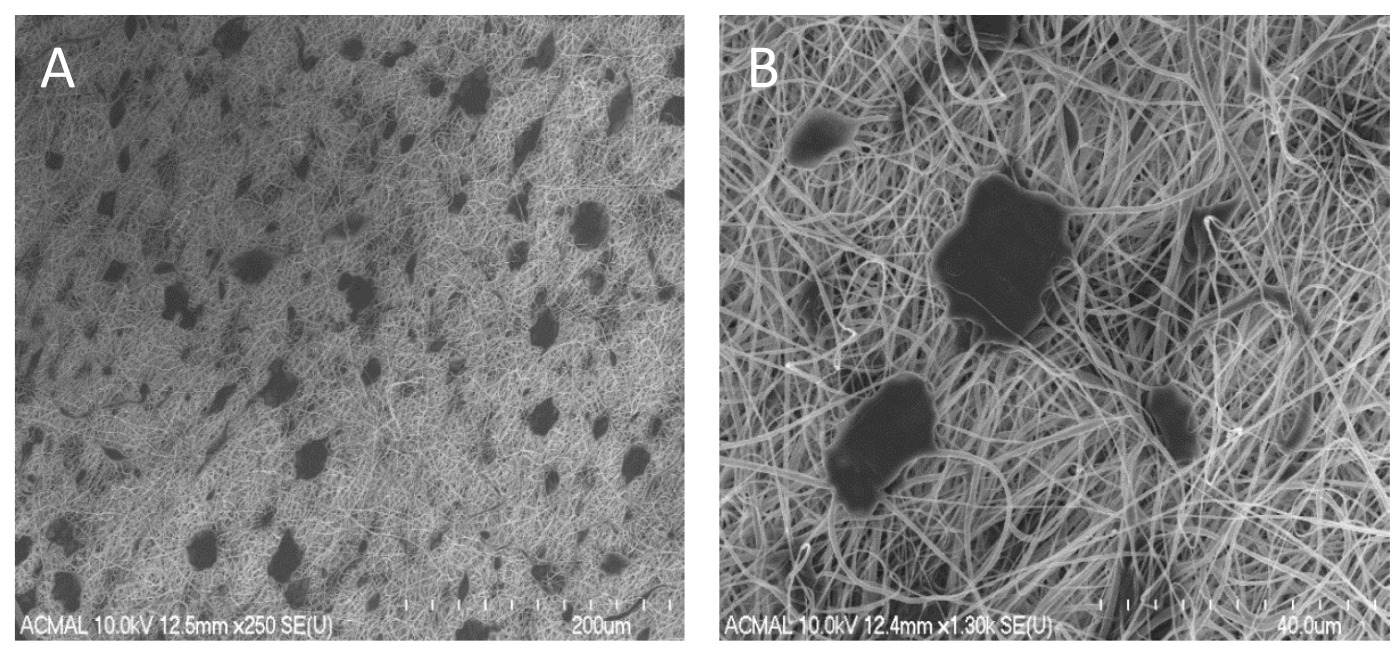

Figure 6.6 shows the FESEM image of the scaffold after cell seeding. The cells were fixed after day 3 and imaged. Figure 6.6 A shows a low magnification image and Figure 6.6 B shows a high magnification image of the scaffold seeded with cells.

The FESEM images of PCL-PVDF as seen in figure 6.6 help in identifying the cellular interactions on the scaffold. PCL-PVDF fibers had better cell attachment and cell migration than PCL. The cells were spread throughout the scaffold. PCL-PVDF contains PVDF in the $\beta$-phase which makes the scaffold piezoelectric. The presence of electroactivity in scaffolds has been previously shown to induce cellular alignment and proliferation. However, the amorphous behavior as seen from the XRD spectra and the ductility make it a poor choice for cellular scaffolds. The cells are aligned and have migrated because of the possible generation of electric charges with forces exerted by the cells on the nanofibers and the less hydrophobic nature of the scaffold as compared to PCL. 


\section{Chapter 7: PCL-PANI-PVDF scaffolds}

\subsection{Introduction}

The PCL-PVDF scaffolds did not have the cellular migration and infiltration to make it a truly bio mimicking scaffold. The lack of conductivity could have been one of the possible reasons. To overcome this difficulty, a combination of a viscoelastic polymer, piezoelectric polymer and a semi-conducting polymer in a single was hypothesized to be the ideal combination in order to fabricate an ideal scaffold. Previous research has focused on either the use of a conducting polymer with a compatible polymer or the combination of piezoelectric-conducting polymer [87]. A unique combination of viscoelastic, conducting and piezoelectric will provide the necessary stiffness and conductivity

\subsubsection{Polyaniline}

Polyaniline (PANI) is a biocompatible semi-conducting polymer which is also known as aniline black. It exists in various oxidation states varying from the fully oxidized state (pernigraniline), half oxidized state (emeraldine) to the fully reduced state (leucoemeraldine). Emeraldine is the most stable of these and in the presence of protonic acids forms emeraldine salt. The emeraldine salt is conductive and the mechanism of conduction is through the movement of electrons through the $\pi$-bonds. It has been used extensively for technological applications. PANI provides a means to make electroactive scaffolds and hence has been used as composites for fabrication of scaffolds for cardiac, vascular and skeletal muscles [88].

\subsection{Design of experiments}

\subsubsection{Aligned scaffold}

\subsubsection{Methods}

A $25 \mathrm{mg}$ emeraldine base of PANI and 25mg HCSA were suspended in $10 \mathrm{ml}$ chloroform. The solution was stirred and sonicated alternatively. The resulting solution was syringe filtered using a $0.22 \mathrm{um}$ syringe filter and 20\% PCL was dissolved in it before electrospinning. A $15 \%$ PVDF solution in $7 \mathrm{ml} \mathrm{DMF}$ and $3 \mathrm{~mL}$ acetone was prepared. The two solutions were used for coaxial electrospinning. The former solution was used as the 
core solution while the latter was used as the sheath solution. An applied voltage of 19.5 $\mathrm{kV}$ across a rotating collector rotating at 1000rpm was used. The core solution has a fluid flow of $100 \mu \mathrm{l} / \mathrm{h}$ and the sheath solution has a flow rate of $50 \mu \mathrm{l} / \mathrm{h}$.

\subsubsection{Results and discussion}

The FESEM images of the fibers as seen in figure 7.1 have an aligned nanofibrous morphology. The fibers had a very good alignment but the density of fibers was not sufficient. Additionally, the thickness of the scaffold does not provide a third dimension and hence, the scaffold was not used for cell seeding experiments.

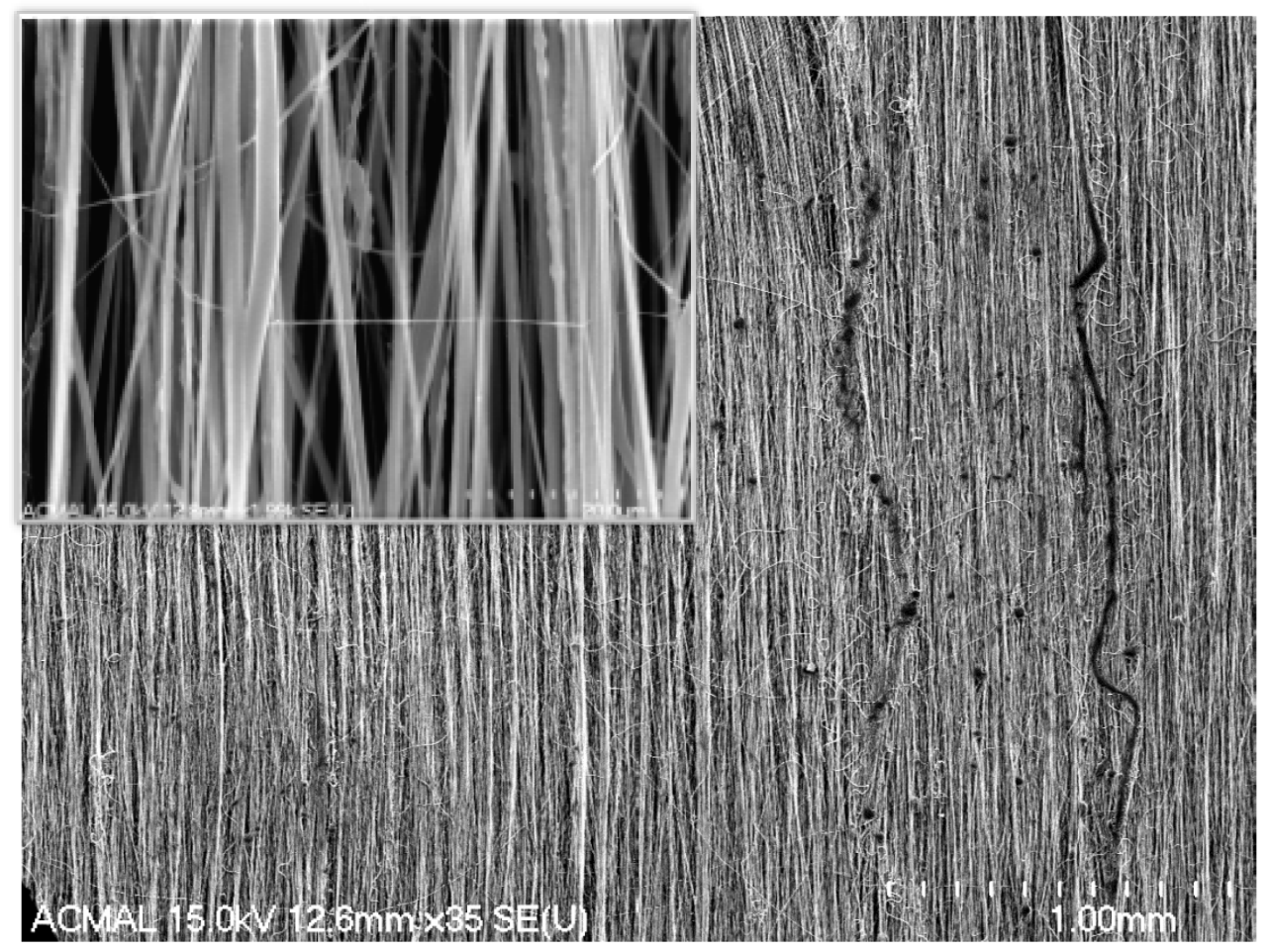

Figure 7.1 shows the FESEM image of the aligned scaffold. The inset image shows a high magnification image of the aligned scaffold.

\subsubsection{Biomimetic scaffold}

\subsubsection{Methods}

The PCL-PANI solution was used as the core solution. 15mg of PANI and HCSA was dissolved in $10 \mathrm{~mL}$ chloroform. The solution was sonicated repeatedly before 
dissolving $1 \mathrm{~g}$ of PCL in it. The PCL-PANI solution was purified using a syringe filter with pore size of $0.22 \mu \mathrm{m}$ to remove the suspensions larger than $0.22 \mu \mathrm{m}$, since the doped form of PANI is immiscible. The resulting solution was sonicated for 3 hours and monitored carefully to maintain a temperature below $30^{\circ} \mathrm{C}$. The PVDF solution was used as the sheath solution. The 20\% PVDF solution was dissolved in acetone and DMF in ratio 3:7. Coaxial electrospinning was used for electrospinning the nanofibers with a polymer flow rate of $0.24 \mathrm{ml} / \mathrm{h}$ and $0.12 \mathrm{ml} / \mathrm{h}$ for PCL-PANI solution and $20 \%$ PVDF. An applied voltage of $18 \mathrm{kV}$ and rotating collector speed of $750 \mathrm{rpm}$ was used.

\subsubsection{Results and discussion}

The below image in figure 7.2 shows the scaffold after fabrication. The alignment of the fibers is clearly visible to the naked eye.

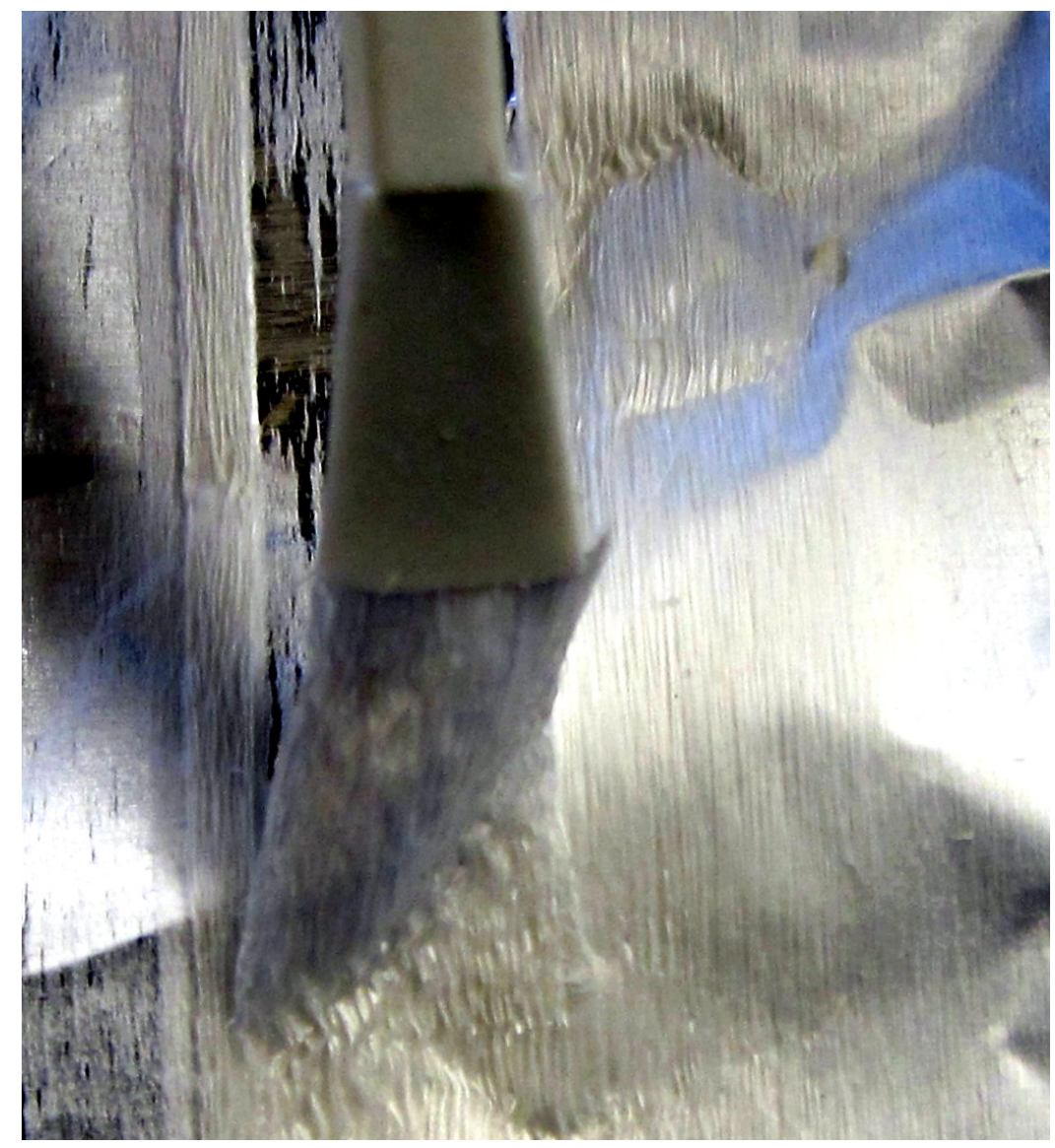

Figure 7.2 shows the biomimetic scaffold after electrospinning. 


\subsection{FESEM}

The scaffold was composed of a dense interconnected network of fibers as seen from the FESEM images in figure 7.3. The fibers are aligned, and have a wide range of diameter from $30 \mathrm{~nm}$ to $2000 \mathrm{~nm}$. The alignment of the fibers had a standard deviation of $8.68^{\circ}$. The dense morphology led to an overlap between different layers of the fibers giving the 3D scaffold necessary thickness required for cell seeding and porosity for mass transport through the different layers as seen from the inset in figure 7.3. The larger diameter fibers form periodic alternating patterns with the smaller diameter fibers. Polymer flow rate, differential solubility of polymers in solvents and the voltage used causes differential jet splitting which leads to the unique pattern of nanofibers [89]. Alternatively, the larger diameter fibers were better aligned than the smaller diameter fibers. This is because the critical uptake velocity of the smaller diameter is much higher than the larger diameter fibers. This causes differential alignment with lower alignment in the smaller diameter fibers. 


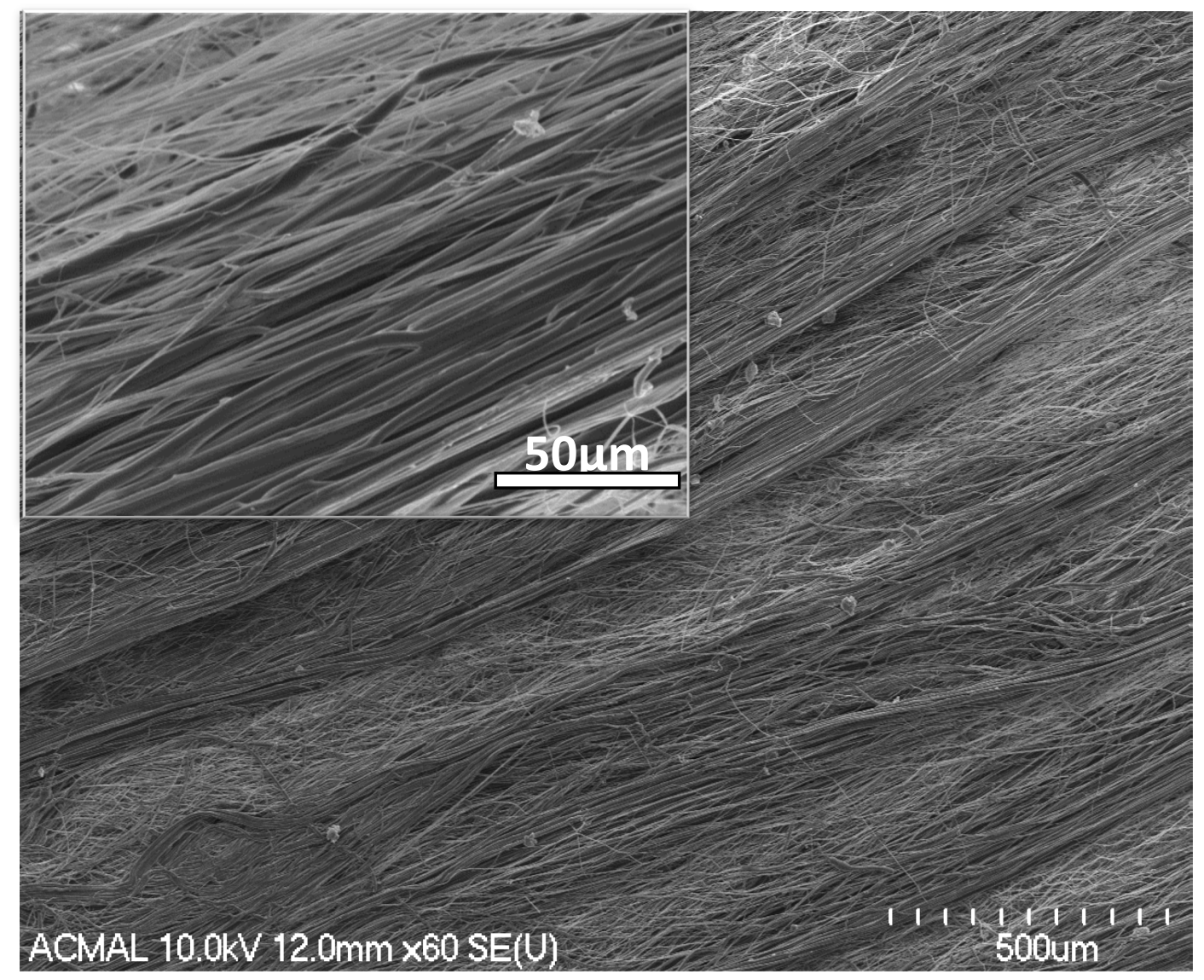

Figure 7.3 shows the FESEM image of the biomimetic scaffold. Inset shows a high magnification image of the same.

\subsection{FTIR}

The surface functional groups of the scaffolds were analyzed by FTIR as seen in figure 7.4. The spectra obtained was used for identifying the distinctive peaks corresponding to the polymer and their phase. Table 7.1 lists all the characteristic peaks of the polymers present in the scaffold. The distinguishing peaks of PCL at $1167 \mathrm{~cm}^{-1}$ (C-O stretching), $2866 \mathrm{~cm}^{-1}$ (symmetric $\mathrm{CH}_{2}$ stretching), $2944 \mathrm{~cm}^{-1}$ (asymmetric $\mathrm{CH}_{2}$ stretching), $1722 \mathrm{~cm}^{-1}(\mathrm{C}=\mathrm{O}$ stretching $)$ and a strong intensity peak at $1293 \mathrm{~cm}^{-1}(\mathrm{C}-\mathrm{O}$ and $\mathrm{C}-\mathrm{C}$ stretching in the crystalline phase of PCL). PVDF has a low intensity peak at $840 \mathrm{~cm}^{-1}$ which is specific to the $\mathrm{CH}_{2}$ rocking in PVDF and corresponds to the $\beta$-phase. The $\beta$-phase of PVDF makes the polymer piezoelectric and thus imparts a certain degree of 
piezoelectricity to the scaffold. PANI can have many peaks which is dependent on the synthesis of the polymer. The amine region is specific to all the PANI and unlike Quinone is not reaction dependent. The minor peak at $3442 \mathrm{~cm}^{-1}$ (N-H stretching) is specific to PANI as no other polymer has amine bonds [90]. The intensity of the peak is low because of the relatively small quantity used for preparation of the scaffold.

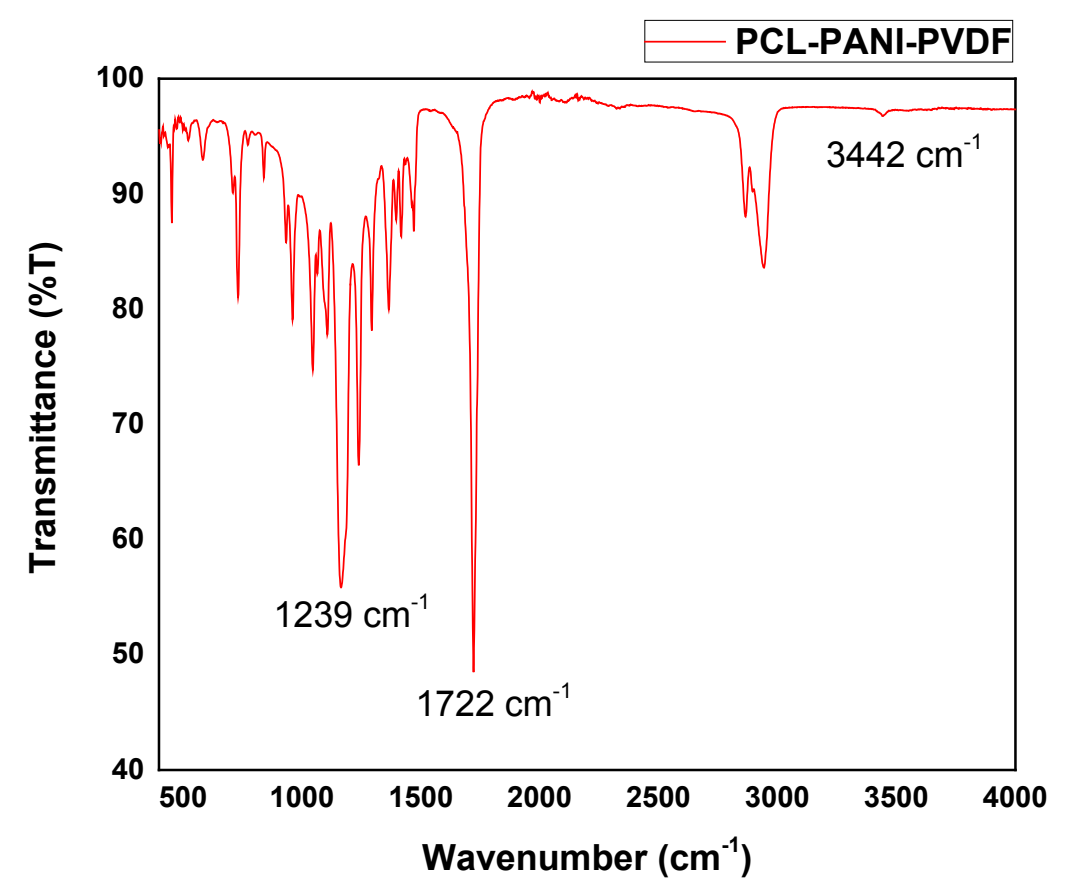

Figure 7.4 shows the FTIR spectrum of the biomimetic scaffold from a region of $400 \mathrm{~cm}^{-}$ ${ }^{1}$ to $4000 \mathrm{~cm}^{-1}$ 
Table 7.1: A list of all the major peaks from FTIR spectrum specific to each polymer and the description of the vibrations

\begin{tabular}{|c|c|c|}
\hline Wavenumbers $\left(\mathrm{cm}^{-1}\right)$ & Description of vibrations & Polymer \\
\hline 1722 & $\mathrm{C}=\mathrm{O}$ stretching & $\mathrm{PCL}$ \\
\hline $\begin{array}{c}2943 \text { (asymmetric), } \\
2866 \text { (symmetric) }\end{array}$ & $\mathrm{CH}$ bending & $\mathrm{PCL}$ \\
\hline $\begin{array}{c}1239 \text { (asymmetric) } \\
1107,1045\end{array}$ & $\mathrm{C}-\mathrm{O}-\mathrm{C}$ stretching & $\mathrm{PCL}$ \\
\hline 1167 & $\mathrm{C}-\mathrm{O}$ stretching & $\mathrm{PCL}$ \\
\hline 1293 & $\begin{array}{c}\mathrm{C}-\mathrm{O} \text { and } \mathrm{C}-\mathrm{C} \text { stretching } \\
\text { in the crystalline phase })\end{array}$ & $\mathrm{PCL}$ \\
\hline 840 & $\mathrm{CH} 2$ rocking & $\beta-\mathrm{PVDF}$ \\
\hline 582 & $\mathrm{C}=\mathrm{O}$ wag & $\mathrm{PCL}$ \\
\hline 3442 & $\mathrm{~N}-\mathrm{H}$ stretching & PANI \\
\hline
\end{tabular}




\subsection{XRD}

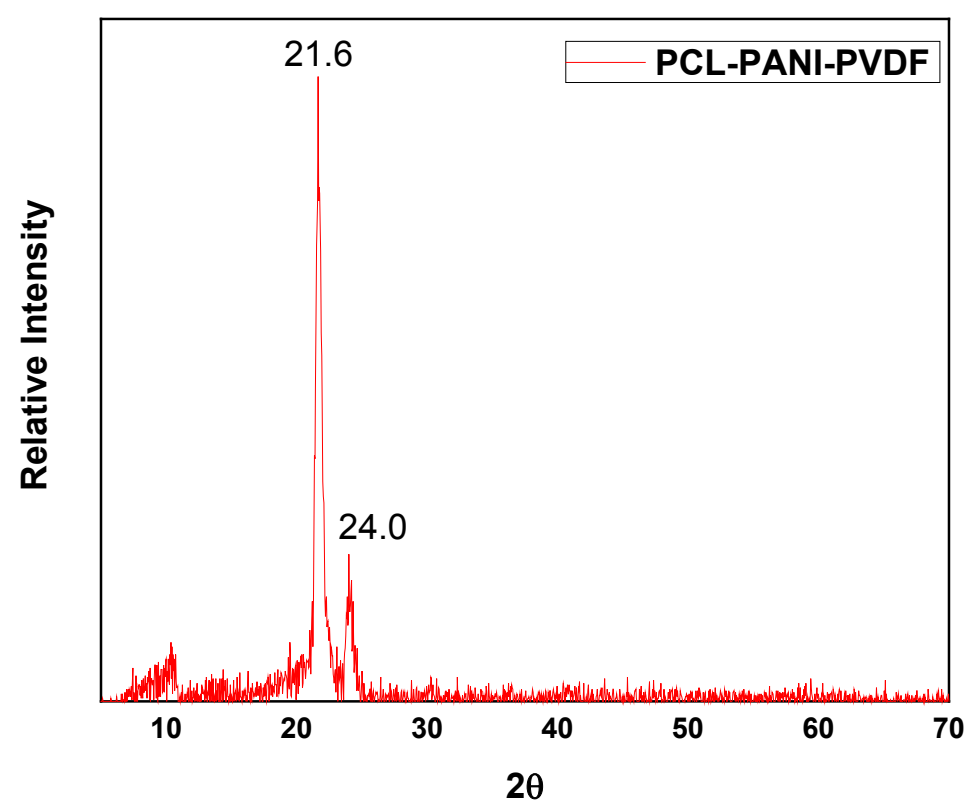

Figure 7.5 shows the XRD spectrum of the biomimetic scaffold.

The XRD spectrum for the scaffold showed diffraction peaks at $2 \theta$ values of $21.6^{\circ}$ and $24.0^{\circ}$ as seen in figure 7.5 . The percentage crystallinity of the scaffold was calculated to be $65.3 \%$. The percentage crystallinity present in the scaffold is because of the high voltage used during electrospinning. The use of compatible solvents and the low flow rate allows more time for polarization which leads to microfibirillation or formation of microfibers. The alignment along the axis thereby increases the order in the system and thus increases the crystallinity. The XRD results agree well with the crystalline PCL bonds at $1293 \mathrm{~cm}^{-1}$ from the FTIR spectra. 


\subsection{DMA}

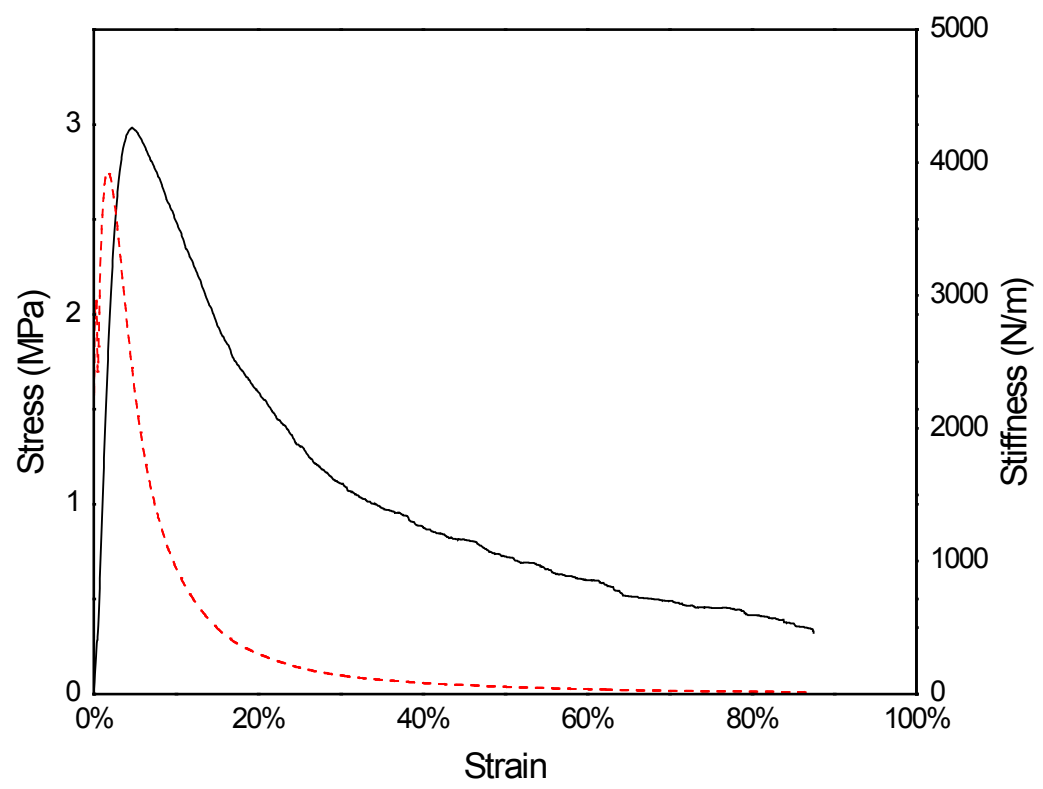

Figure 7.6 shows the stress-strain-stiffness plot of the biomimetic scaffold.

Table 7.2: The mechanical properties of the PCL-PANI-PVDF biomimetic scaffold calculated from the stress-strain-stiffness plot.

\begin{tabular}{|c|c|}
\hline Young's Modulus & $1.01 \mathrm{MPa}$ \\
\hline Ultimate Tensile Strength & $2.98 \mathrm{MPa}$ \\
\hline Elongation at Fracture (\%) & $87.51 \%$ \\
\hline Modulus of Toughness & $94.25 \mathrm{MPa}$ \\
\hline Modulus of resilience & $9.17 \mathrm{MPa}$ \\
\hline
\end{tabular}

The mechanical properties of the scaffold determined from the stress-strainstiffness graph is shown in figure 7.6. The calculated values for the scaffold are tabulated in table 7.2. The plot shows a very high stiffness till yield point is reached. The initial stiffness of the polymer can be attributed to the dense interconnected morphology of the 
fibers. Once the yield point is reached, the smaller fibers tend to break followed by the larger fibers. This reduces the stiffness until fracture point is reached. The increased plastic region helps in increasing the modulus of toughness of the scaffolds. Additionally, the microfibrillation present in the scaffolds helps in the high Young's modulus and modulus of resilience.

\subsection{Cell seeding experiments}

\subsection{Fluorescent microscopy}
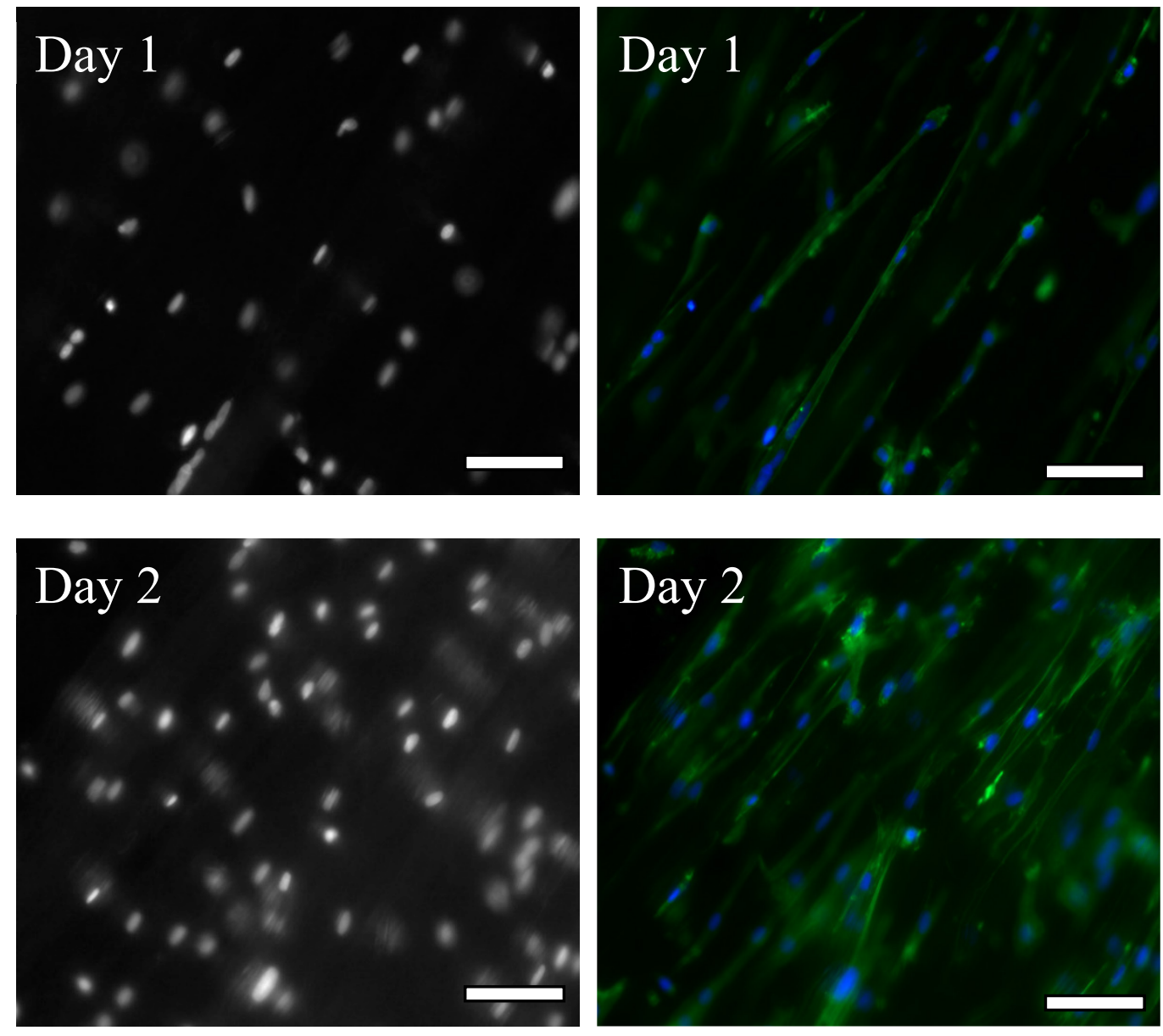

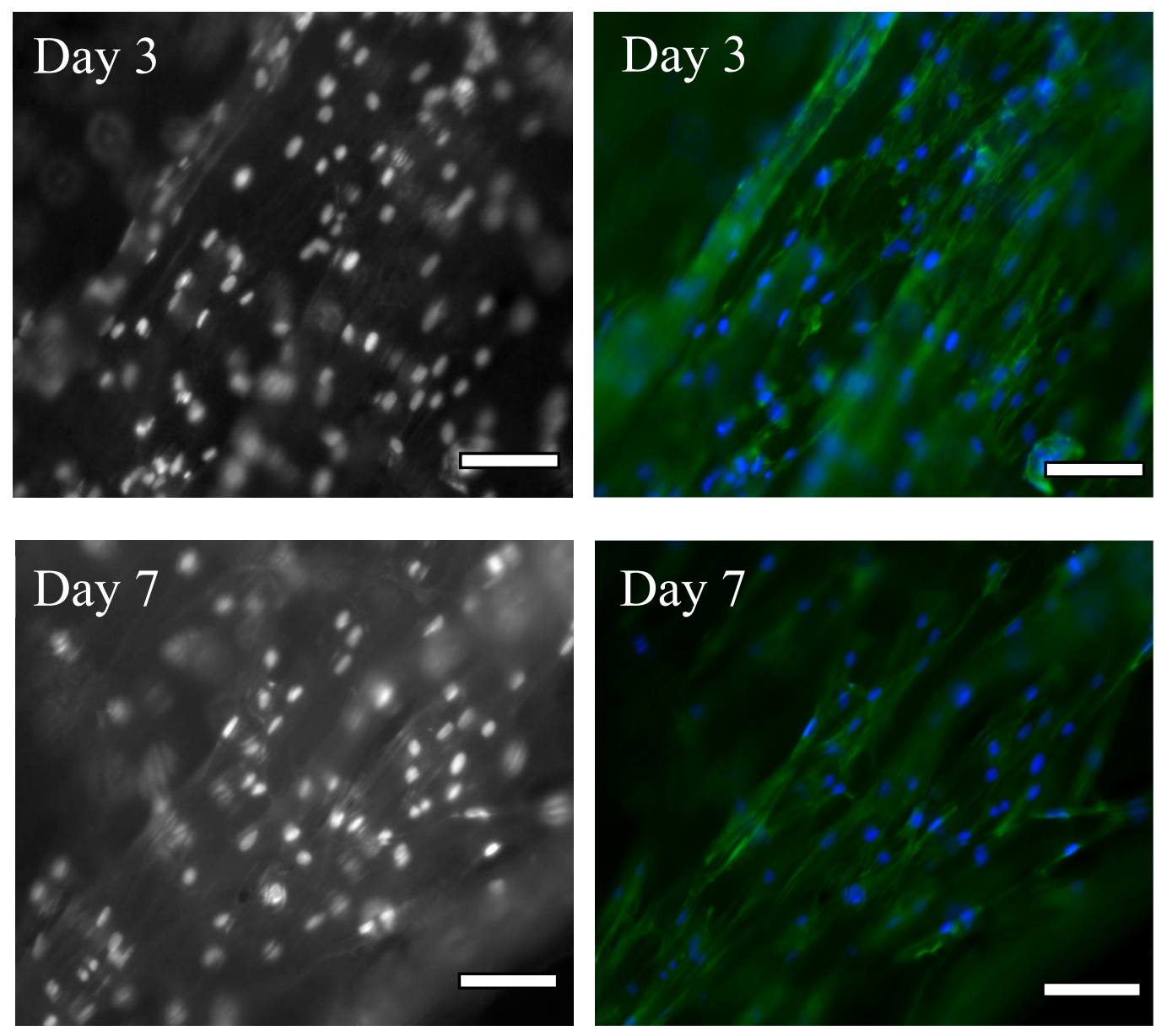

Figure 7.7 shows the cells seeded on the scaffolds after immunofluorescent staining on days 1, 2, 3 and 7 . The images on the left column show the DAPI stained cells while the images on the right show the cells stained with DAPI and Alexa Fluor. The blue color (DAPI) represents the nucleus and the green color (Alexa Fluor) represents the actin filaments.

The scaffolds are cell seeding had actin spreading throughout the scaffold. The spreading of the actin filaments can be seen from the images taken from cells fixed on the scaffolds at different days as seen in figure 7.7. The scaffolds had no cell accumulation and high alignment. Most importantly, the cells showed greater degree of scaffold infiltration previously not seen in any of the other scaffolds. The blurred regions present is because of 
the infiltration of the scaffolds and migration to all regions in the $3 \mathrm{D}$ space. The shape of the nucleus is elliptical, as seen from the DAPI stains in figure 7.7 shows the cell proliferation of the cells.

\subsection{FESEM imaging of cell seeded scaffolds}
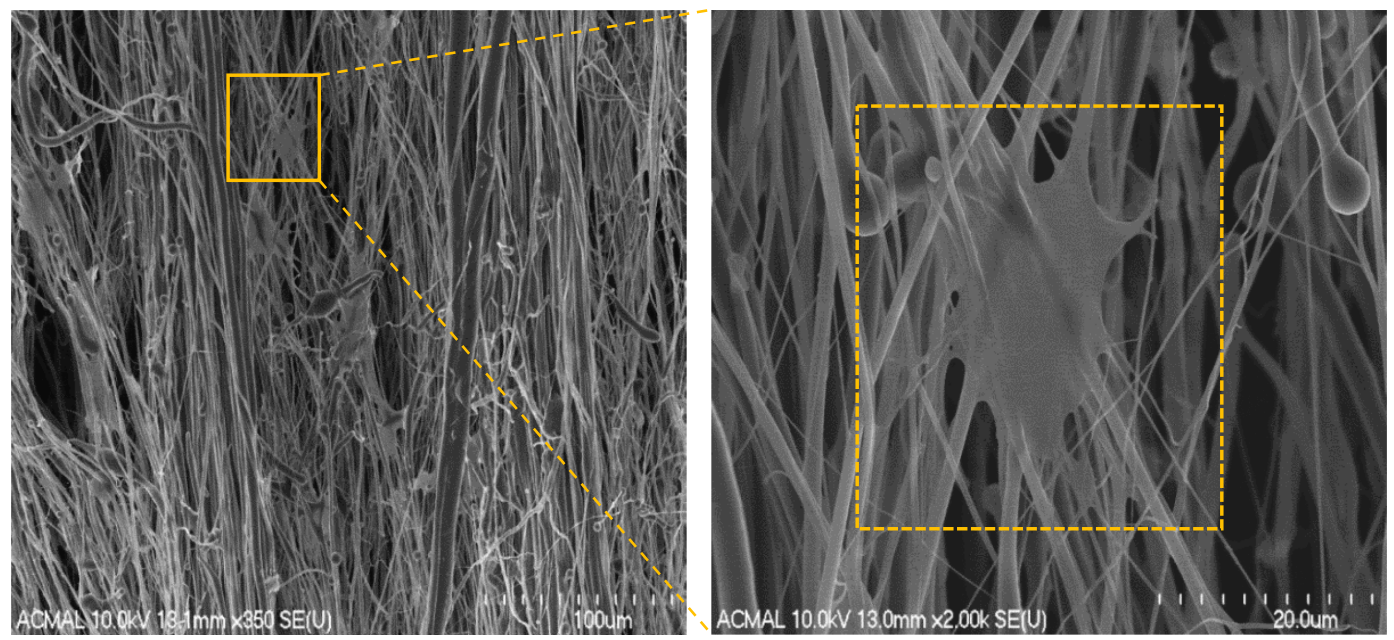

Figure 7.8 shows the FESEM image of the scaffold seeded with cells after 7 days of growth.

The scaffolds seeded with cells were also imaged with FESEM as seen from figure 7.8. The top layer of cells on day 7 of cell seeding look devoid of cells. A magnified image of the scaffold reveals the presence of cells at different depths of the scaffold intertwined over the fibers. The alignment of the cells was not affected by the sample preparation. The scaffolds had even growth and had a higher cell density than the previous scaffolds. The yellow box shows a high magnified image of the cells adhered to the scaffold. Similar cells were visible throughout the scaffold at lower depths of the scaffold. The fluorescent stained images showed the cells had alignment and proliferation. Thus, a truly biomimetic acellular scaffold was designed and characterized. 


\subsection{Conclusions}

Table 7.3 summarizes the different PCL-PANI-PVDF based scaffolds

\begin{tabular}{|c|c|c|c|}
\hline Type of scaffold & Morphology & Hypothesis & Challenges faced \\
\hline Aligned scaffold & Aligned fibers & $\begin{array}{c}\text { The use of aligned } \\
\text { might help in } \\
\text { increasing scaffold } \\
\text { infiltration }\end{array}$ & $\begin{array}{c}\text { The use of volatile } \\
\text { solvents prevented } \\
\text { the continuous } \\
\text { deposition of } \\
\text { nanofibers. Also, } \\
\text { the density of } \\
\text { fibers in the } \\
\text { scaffold was low } \\
\text { and thickness was } \\
\text { limited. }\end{array}$ \\
\hline 3D scaffold & $\begin{array}{c}\text { Thick dense } \\
\text { scaffold with } \\
\text { aligned fibers with } \\
\text { a broad range of } \\
\text { diameters forming } \\
\text { bands. }\end{array}$ & $\begin{array}{c}\text { porosity might help } \\
\text { in scaffold } \\
\text { infiltration and } \\
\text { high cell density. }\end{array}$ & $\begin{array}{c}\text { The thickness and } \\
\text { and scaffold } \\
\text { infiltration was the } \\
\text { best among all the } \\
\text { scaffolds }\end{array}$ \\
\hline
\end{tabular}

Table 7.3 summarizes the different scaffolds that were fabricated and the challenges faced with the scaffolds. The material used and the method of preparation of the $3 \mathrm{D}$ scaffold provided the microenvironment for cellular infiltration and supporting high cell density on the scaffold. The dipole movement in the scaffold helped in the cellular adhesion. 


\section{Conclusion}

Electrospinning is a very promising technique for creating acellular scaffolds for tissue engineering which can mimic the 3D architecture of the natural tissue. Many materials have been used for fabrication of electrospun scaffold. In this study, the focus was on the design of scaffold which mimics the 3D in vivo environment using different synthetic materials. Different morphologies of the nanofiber scaffolds were fabricated using electrospinning. The scaffolds were seeded with cells to determine the most favorable scaffold for tissue engineering applications.

PCL was initially used based on literature survey for the fabrication of scaffolds. Different architectures of the scaffold were created and seeded with cells. The cellular response to the scaffold was observed and modifications were made. The PCL scaffolds had low cellular proliferation, cellular alignment and scaffold infiltration. To promote cellular alignment, a piezoelectric polymer, PVDF was used along with PCL for the fabrication of an electroactive scaffold. The cellular response to the scaffolds obtained from different concentrations of PCL and PVDF was investigated. The PCL-PVDF scaffolds had poor cellular infiltration but had cellular alignment and migration which was not seen in the PCL scaffolds. Thus, to promote scaffold infiltration, a semi-conductive polymer PANI was introduced. Coaxial electrospinning was used for the fabrication of the PCLPANI-PVDF scaffold. Different concentrations were used and different morphologies were fabricated and tested. The cells had very good cellular proliferation, alignment and scaffold infiltration. The 3D scaffold had a very dense nanofiber architecture providing the necessary mass transport to all depths of the scaffold. This scaffold has the potential to be used as acellular patches for wound healing, tissue regeneration and organ engineering. Furthermore, owing to the piezoelectric and conducting properties, the nanofibers have potential applications in sensors and energy harvesting applications. 


\section{Future Work}

The current work paves the way for research into acellular scaffolds. Rat cardiomyoblasts have been used for cell seeding experiments. The cells could proliferate and align on the scaffold without the introduction of growth factors or the application of mechanical or electrical signals to provide cues. This feature can be potentially used for the fabrication of acellular cardiac patches. Further in vitro and in vivo tests are required in order to determine the effectiveness of the biomimetic scaffold for different cell types and also to check hot cell recruitment on the scaffold. The method of fabrication of the fibers provides room for tuning the parameters to suit the requirements for functioning as scaffold for other cell types. Thus, they can be used for wound healing applications. The scaffolds can also be used as cellularized scaffold for organ engineering.

The electro activity of the scaffold can be used for developing a new range of sensors which can be integrated with the body. The scaffold can also be used for fabrication of neural interfaces and deep neural stimulation. 


\section{References}

[1] F. Pampaloni, E. G. Reynaud, and E. H. K. Stelzer, "The third dimension bridges the gap between cell culture and live tissue," Nat Rev Mol Cell Biol, vol. 8, pp. 839-845, 10//print 2007.

[2] L. G. Griffith and G. Naughton, "Tissue Engineering--Current Challenges and Expanding Opportunities," Science, vol. 295, p. 1009, 2002.

[3] A. Hansen, A. Eder, M. Bönstrup, M. Flato, M. Mewe, S. Schaaf, et al., "Development of a drug screening platform based on engineered heart tissue," Circulation research, vol. 107, pp. 35-44, 2010.

[4] J. P. Vacanti and R. Langer, "Tissue engineering: the design and fabrication of living replacement devices for surgical reconstruction and transplantation," The lancet, vol. 354, pp. S32-S34, 1999.

[5] S. F. Badylak, D. Taylor, and K. Uygun, "Whole-organ tissue engineering: decellularization and recellularization of three-dimensional matrix scaffolds," Annual review of biomedical engineering, vol. 13, pp. 27-53, 2011.

[6] R. Langer, "Perspectives and challenges in tissue engineering and regenerative medicine," Advanced Materials, vol. 21, pp. 3235-3236, 2009.

[7] D. W. Hutmacher, R. E. Horch, D. Loessner, S. Rizzi, S. Sieh, J. C. Reichert, et al., "Translating tissue engineering technology platforms into cancer research," Journal of cellular and molecular medicine, vol. 13, pp. 1417-1427, 2009.

[8] L. G. Griffith and M. A. Swartz, "Capturing complex 3D tissue physiology in vitro," Nature reviews Molecular cell biology, vol. 7, pp. 211-224, 2006.

[9] R. Langer and J. Vacanti, "Tissue engineering," Science, vol. 260, pp. 920-926, 1993. 
[10] A. Schäffler and C. Büchler, "Concise review: adipose tissue-derived stromal cells-basic and clinical implications for novel cell-based therapies," Stem cells, vol. 25, pp. 818-827, 2007.

[11] T. Boontheekul and D. J. Mooney, "Protein-based signaling systems in tissue engineering," Current opinion in biotechnology, vol. 14, pp. 559-565, 2003.

[12] S. Takagi, "Scaffold-Based Tissue Engineering," in Myocardial Tissue Engineering, ed: Pan Stanford, 2015, pp. 89-105.

[13] B. Chan and K. Leong, "Scaffolding in tissue engineering: general approaches and tissue-specific considerations," European spine journal, vol. 17, pp. 467-479, 2008.

[14] N. A. Peppas and R. Langer, "New challenges in biomaterials," Science, vol. 263, pp. 1715-1721, 1994.

[15] M. M. Stevens and J. H. George, "Exploring and engineering the cell surface interface," Science, vol. 310, pp. 1135-1138, 2005.

[16] D. W. Hutmacher, M. Sittinger, and M. V. Risbud, "Scaffold-based tissue engineering: rationale for computer-aided design and solid free-form fabrication systems," TRENDS in Biotechnology, vol. 22, pp. 354-362, 2004.

[17] S. Levenberg, N. F. Huang, E. Lavik, A. B. Rogers, J. Itskovitz-Eldor, and R. Langer, "Differentiation of human embryonic stem cells on three-dimensional polymer scaffolds," Proceedings of the National Academy of Sciences, vol. 100, pp. 12741-12746, 2003.

[18] L. Ghasemi-Mobarakeh, M. P. Prabhakaran, M. Morshed, M. H. Nasr-Esfahani, H. Baharvand, S. Kiani, et al., "Application of conductive polymers, scaffolds and electrical stimulation for nerve tissue engineering," Journal of tissue engineering and regenerative medicine, vol. 5, pp. e17-e35, 2011. 
[19] G. Chen, T. Ushida, and T. Tateishi, "Scaffold design for tissue engineering," Macromolecular Bioscience, vol. 2, pp. 67-77, 2002.

[20] T. Telemeco, C. Ayres, G. Bowlin, G. Wnek, E. Boland, N. Cohen, et al., "Regulation of cellular infiltration into tissue engineering scaffolds composed of submicron diameter fibrils produced by electrospinning," Acta biomaterialia, vol. 1, pp. 377-385, 2005.

[21] F. Causa, P. A. Netti, and L. Ambrosio, "A multi-functional scaffold for tissue regeneration: The need to engineer a tissue analogue," Biomaterials, vol. 28, pp. 5093$5099,12 / / 2007$.

[22] S. J. Hollister, R. Maddox, and J. M. Taboas, "Optimal design and fabrication of scaffolds to mimic tissue properties and satisfy biological constraints," Biomaterials, vol. 23, pp. 4095-4103, 2002.

[23] S. Sundelacruz, M. Levin, and D. L. Kaplan, "Role of membrane potential in the regulation of cell proliferation and differentiation," Stem cell reviews and reports, vol. 5, pp. 231-246, 2009.

[24] S. Sundelacruz, M. Levin, and D. L. Kaplan, "Membrane potential controls adipogenic and osteogenic differentiation of mesenchymal stem cells," PLoS One, vol. 3, p. e3737, 2008.

[25] S. J. Hollister, "Porous scaffold design for tissue engineering," Nature materials, vol. 4, pp. 518-524, 2005.

[26] W. J. Li, C. T. Laurencin, E. J. Caterson, R. S. Tuan, and F. K. Ko, "Electrospun nanofibrous structure: a novel scaffold for tissue engineering," Journal of biomedical materials research, vol. 60, pp. 613-621, 2002.

[27] B. D. Ratner and S. J. Bryant, "Biomaterials: Where we have been and where we are going," Annual Review of Biomedical Engineering, vol. 6, pp. 41-75, 2004. 
[28] H. Shin, S. Jo, and A. G. Mikos, "Biomimetic materials for tissue engineering," Biomaterials, vol. 24, pp. 4353-4364, Nov 2003.

[29] S. Yang, K.-F. Leong, Z. Du, and C.-K. Chua, "The design of scaffolds for use in tissue engineering. Part I. Traditional factors," Tissue engineering, vol. 7, pp. 679-689, 2001.

[30] B.-S. Kim and D. J. Mooney, "Development of biocompatible synthetic extracellular matrices for tissue engineering," Trends in biotechnology, vol. 16, pp. 224230, 1998.

[31] G. Chan and D. J. Mooney, "New materials for tissue engineering: towards greater control over the biological response," Trends in biotechnology, vol. 26, pp. 382-392, 2008.

[32] P. B. Malafaya, G. A. Silva, and R. L. Reis, "Natural-origin polymers as carriers and scaffolds for biomolecules and cell delivery in tissue engineering applications," Advanced drug delivery reviews, vol. 59, pp. 207-233, 2007.

[33] S. Heydarkhan-Hagvall, K. Schenke-Layland, A. P. Dhanasopon, F. Rofail, H. Smith, B. M. Wu, et al., "Three-dimensional electrospun ECM-based hybrid scaffolds for cardiovascular tissue engineering," Biomaterials, vol. 29, pp. 2907-2914, 2008.

[34] J. Baier Leach, K. A. Bivens, C. W. Patrick Jr, and C. E. Schmidt, "Photocrosslinked hyaluronic acid hydrogels: natural, biodegradable tissue engineering scaffolds," Biotechnology and bioengineering, vol. 82, pp. 578-589, 2003.

[35] S. Suganya, J. Venugopal, S. A. Mary, S. Ramakrishna, B. Lakshmi, and V. G. Dev, "Aloe vera incorporated biomimetic nanofibrous scaffold: a regenerative approach for skin tissue engineering," Iranian Polymer Journal, vol. 23, pp. 237-248, 2014.

[36] D. J. Modulevsky, C. Lefebvre, K. Haase, Z. Al-Rekabi, and A. E. Pelling, "Apple derived cellulose scaffolds for 3D mammalian cell culture," PloS one, vol. 9, p. e97835, 2014. 
[37] N. Reddy and Y. Yang, "Potential of plant proteins for medical applications," Trends in Biotechnology, vol. 29, pp. 490-498, 10// 2011.

[38] F. A. Müller, L. Müller, I. Hofmann, P. Greil, M. M. Wenzel, and R. Staudenmaier, "Cellulose-based scaffold materials for cartilage tissue engineering," Biomaterials, vol. 27, pp. 3955-3963, 2006.

[39] J.-K. F. Suh and H. W. Matthew, "Application of chitosan-based polysaccharide biomaterials in cartilage tissue engineering: a review," Biomaterials, vol. 21, pp. 2589$2598,2000$.

[40] S. Tarafder, V. K. Balla, N. M. Davies, A. Bandyopadhyay, and S. Bose, "Microwave-sintered 3D printed tricalcium phosphate scaffolds for bone tissue engineering," Journal of tissue engineering and regenerative medicine, vol. 7, pp. 631641,2013

[41] V. Mouriño, J. P. Cattalini, J. A. Roether, P. Dubey, I. Roy, and A. R. Boccaccini, "Composite polymer-bioceramic scaffolds with drug delivery capability for bone tissue engineering," Expert opinion on drug delivery, vol. 10, pp. 1353-1365, 2013.

[42] W. Li, P. Nooeaid, J. A. Roether, D. W. Schubert, and A. R. Boccaccini, "Preparation and characterization of vancomycin releasing PHBV coated 45S5 Bioglass $($ based glass-ceramic scaffolds for bone tissue engineering," Journal of the European Ceramic Society, vol. 34, pp. 505-514, 2014.

[43] M. Okamoto and B. John, "Synthetic biopolymer nanocomposites for tissue engineering scaffolds," Progress in Polymer Science, vol. 38, pp. 1487-1503, 2013.

[44] B. Guo and P. X. Ma, "Synthetic biodegradable functional polymers for tissue engineering: a brief review," Science China Chemistry, vol. 57, pp. 490-500, 2014.

[45] P. Sepulveda, J. R. Jones, and L. L. Hench, "Bioactive sol-gel foams for tissue repair," Journal of biomedical materials research, vol. 59, pp. 340-348, 2002. 
[46] S. H. Oh, S. G. Kang, E. S. Kim, S. H. Cho, and J. H. Lee, "Fabrication and characterization of hydrophilic poly (lactic-co-glycolic acid)/poly (vinyl alcohol) blend cell scaffolds by melt-molding particulate-leaching method," Biomaterials, vol. 24, pp. 4011-4021, 2003.

[47] A. G. Mikos, Y. Bao, L. G. Cima, D. E. Ingber, J. P. Vacanti, and R. Langer, "Preparation of poly(glycolic acid) bonded fiber structures for cell attachment and transplantation," Journal of Biomedical Materials Research, vol. 27, pp. 183-189, 1993.

[48] Y. S. Nam and T. G. Park, "Porous biodegradable polymeric scaffolds prepared by thermally induced phase separation," Journal of biomedical materials research, vol. 47, pp. 8-17, 1999.

[49] A. Kramschuster and L. S. Turng, "An injection molding process for manufacturing highly porous and interconnected biodegradable polymer matrices for use as tissue engineering scaffolds," Journal of Biomedical Materials Research Part B: Applied Biomaterials, vol. 92, pp. 366-376, 2010.

[50] C. X. F. Lam, X. Mo, S.-H. Teoh, and D. Hutmacher, "Scaffold development using 3D printing with a starch-based polymer," Materials Science and Engineering: C, vol. 20, pp. 49-56, 2002.

[51] X. Wu, Y. Liu, X. Li, P. Wen, Y. Zhang, Y. Long, et al., "Preparation of aligned porous gelatin scaffolds by unidirectional freeze-drying method," Acta biomaterialia, vol. 6, pp. 1167-1177, 2010.

[52] X. Zong, H. Bien, C.-Y. Chung, L. Yin, D. Fang, B. S. Hsiao, et al., "Electrospun fine-textured scaffolds for heart tissue constructs," Biomaterials, vol. 26, pp. 5330-5338, 2005.

[53] T. J. Sill and H. A. von Recum, "Electrospinning: applications in drug delivery and tissue engineering," Biomaterials, vol. 29, pp. 1989-2006, 2008. 
[54] D. Li and Y. Xia, "Electrospinning of nanofibers: reinventing the wheel?," Advanced materials, vol. 16, pp. 1151-1170, 2004.

[55] L. Persano, A. Camposeo, C. Tekmen, and D. Pisignano, "Industrial upscaling of electrospinning and applications of polymer nanofibers: a review," Macromolecular Materials and Engineering, vol. 298, pp. 504-520, 2013.

[56] J. Doshi and D. H. Reneker, "Electrospinning process and applications of electrospun fibers," Journal of electrostatics, vol. 35, pp. 151-160, 1995.

[57] Q.P. Pham, U. Sharma, and A. G. Mikos, "Electrospinning of polymeric nanofibers for tissue engineering applications: a review," Tissue engineering, vol. 12, pp. 1197-1211, 2006.

[58] N. Tucker, J. J. Stanger, M. P. Staiger, H. Razzaq, and K. Hofman, "The History of the Science and Technology of Electrospinning from 1600 to 1995," Journal of Engineered Fabrics \& Fibers (JEFF), vol. 7, 2012.

[59] D. H. Reneker and A. L. Yarin, "Electrospinning jets and polymer nanofibers," Polymer, vol. 49, pp. 2387-2425, 5/13/ 2008.

[60] M. M. Hohman, M. Shin, G. Rutledge, and M. P. Brenner, "Electrospinning and electrically forced jets. I. Stability theory," Physics of fluids, vol. 13, pp. 2201-2220, 2001.

[61] Y. Shin, M. Hohman, M. Brenner, and G. Rutledge, "Experimental characterization of electrospinning: the electrically forced jet and instabilities," Polymer, vol. 42, pp. 0995509967, 2001.

[62] W. E. Teo and S. Ramakrishna, "A review on electrospinning design and nanofibre assemblies," Nanotechnology, vol. 17, p. R89, 2006.

[63] G. Larsen, R. Spretz, and R. Velarde-Ortiz, "Use of Coaxial Gas Jackets to Stabilize Taylor Cones of Volatile Solutions and to Induce Particle-to-Fiber Transitions," Advanced Materials, vol. 16, pp. 166-169, 2004. 
[64] C. Thompson, G. G. Chase, A. Yarin, and D. Reneker, "Effects of parameters on nanofiber diameter determined from electrospinning model," Polymer, vol. 48, pp. 69136922, 2007.

[65] A. L. Yarin, S. Koombhongse, and D. H. Reneker, "Taylor cone and jetting from liquid droplets in electrospinning of nanofibers," Journal of applied physics, vol. 90, pp. 4836-4846, 2001.

[66] C. Zhang, X. Yuan, L. Wu, Y. Han, and J. Sheng, "Study on morphology of electrospun poly(vinyl alcohol) mats," European Polymer Journal, vol. 41, pp. 423-432, $3 / / 2005$.

[67] O. Ero-Phillips, M. Jenkins, and A. Stamboulis, "Tailoring crystallinity of electrospun plla fibres by control of electrospinning parameters," Polymers, vol. 4, pp. 1331-1348, 2012.

[68] S. Zhang, W. S. Shim, and J. Kim, "Design of ultra-fine nonwovens via electrospinning of Nylon 6: Spinning parameters and filtration efficiency," Materials \& Design, vol. 30, pp. 3659-3666, 2009.

[69] S. V. Fridrikh, H. Y. Jian, M. P. Brenner, and G. C. Rutledge, "Controlling the fiber diameter during electrospinning," Physical review letters, vol. 90, p. 144502, 2003.

[70] Z. Li and C. Wang, "Effects of working parameters on electrospinning," in Onedimensional nanostructures, ed: Springer, 2013, pp. 15-28.

[71] D. Sun, C. Chang, S. Li, and L. Lin, "Near-field electrospinning," Nano letters, vol. 6, pp. 839-842, 2006.

[72] C. L. Casper, J. S. Stephens, N. G. Tassi, D. B. Chase, and J. F. Rabolt, "Controlling Surface Morphology of Electrospun Polystyrene Fibers: Effect of Humidity and Molecular Weight in the Electrospinning Process," Macromolecules, vol. 37, pp. 573-578, 2004/01/01 2004. 
[73] J. Nam, Y. Huang, S. Agarwal, and J. Lannutti, "Improved cellular infiltration in electrospun fiber via engineered porosity," Tissue engineering, vol. 13, pp. 2249-2257, 2007.

[74] L. Wannatong, A. Sirivat, and P. Supaphol, "Effects of solvents on electrospun polymeric fibers: preliminary study on polystyrene," Polymer International, vol. 53, pp. 1851-1859, 2004.

[75] X. Wang, B. Ding, G. Sun, M. Wang, and J. Yu, "Electro-spinning/netting: a strategy for the fabrication of three-dimensional polymer nano-fiber/nets," Progress in Materials Science, vol. 58, pp. 1173-1243, 2013.

[76] J. S. Lee, K. H. Choi, H. D. Ghim, S. S. Kim, D. H. Chun, H. Y. Kim, et al., "Role of molecular weight of atactic poly(vinyl alcohol) (PVA) in the structure and properties of PVA nanofabric prepared by electrospinning," Journal of Applied Polymer Science, vol. 93, pp. 1638-1646, 2004.

[77] L. Ghasemi-Mobarakeh, M. P. Prabhakaran, M. Morshed, M.-H. Nasr-Esfahani, and S. Ramakrishna, "Electrospun poly ( $\varepsilon$-caprolactone)/gelatin nanofibrous scaffolds for nerve tissue engineering," Biomaterials, vol. 29, pp. 4532-4539, 2008.

[78] M. A. Woodruff and D. W. Hutmacher, "The return of a forgotten polymerpolycaprolactone in the 21st century," Progress in Polymer Science, vol. 35, pp. 1217$1256,2010$.

[79] J. Gunn and M. Zhang, "Polyblend nanofibers for biomedical applications: perspectives and challenges," Trends in Biotechnology, vol. 28, pp. 189-197, 4// 2010.

[80] R. Balint, N. J. Cassidy, and S. H. Cartmell, "Conductive polymers: Towards a smart biomaterial for tissue engineering," Acta Biomaterialia, vol. 10, pp. 2341-2353, 6// 2014.

[81] A. H. Rajabi, M. Jaffe, and T. L. Arinzeh, "Piezoelectric materials for tissue regeneration: a review," Acta biomaterialia, vol. 24, pp. 12-23, 2015. 
[82] X. Liu, X. Wang, H. Zhao, and Y. Du, "Myocardial Cell Pattern on Piezoelectric Nanofiber Mats for Energy Harvesting," Journal of Physics: Conference Series, vol. 557, p. 012057, 2014.

[83] W. H. Jo, S. J. Park, and I. H. Kwon, "Phase behavior of poly ( $\varepsilon$-caprolactone)/poly (vinylidene fluoride) blends," Polymer international, vol. 29, pp. 173-178, 1992.

[84] A. Salimi and A. Yousefi, "Analysis method: FTIR studies of $\beta$-phase crystal formation in stretched PVDF films," Polymer Testing, vol. 22, pp. 699-704, 2003.

[85] P. Martins, A. Lopes, and S. Lanceros-Mendez, "Electroactive phases of poly (vinylidene fluoride): determination, processing and applications," Progress in polymer science, vol. 39, pp. 683-706, 2014.

[86] J. Andrew and D. Clarke, "Effect of electrospinning on the ferroelectric phase content of polyvinylidene difluoride fibers," Langmuir, vol. 24, pp. 670-672, 2008.

[87] A.-D. Bendrea, L. Cianga, and I. Cianga, "Review paper: progress in the field of conducting polymers for tissue engineering applications," Journal of biomaterials applications, vol. 26, pp. 3-84, 2011.

[88] T. H. Qazi, R. Rai, and A. R. Boccaccini, "Tissue engineering of electrically responsive tissues using polyaniline based polymers: A review," Biomaterials, vol. 35, pp. 9068-9086, 11// 2014.

[89] D. Lukáš, A. Sarkar, L. Martinová, K. Vodsed'álková, D. Lubasová, J. Chaloupek, et al., "Physical principles of electrospinning (Electrospinning as a nano-scale technology of the twenty-first century)," Textile Progress, vol. 41, pp. 59-140, 2009/05/29 2009.

[90] M. Trchová, I. Šeděnková, E. Tobolková, and J. Stejskal, "FTIR spectroscopic and conductivity study of the thermal degradation of polyaniline films," Polymer Degradation and Stability, vol. 86, pp. 179-185, 2004. 